Universidad
de Alcalá

BIBLIOTECA

Document downloaded from the institutional repository of the University of Alcala: http://dspace.uah.es/dspace/

This is a postprint version of the following published document:

Castro, J. et al., 2017. Effective nut dispersal by magpies ( Pica pica L.) in a Mediterranean agroecosystem. Oecologia, 184(1), pp.183-192.

Available at http://dx.doi.org/10.1007/s00442-017-3848-x

(C) 2017 Springer Verlag
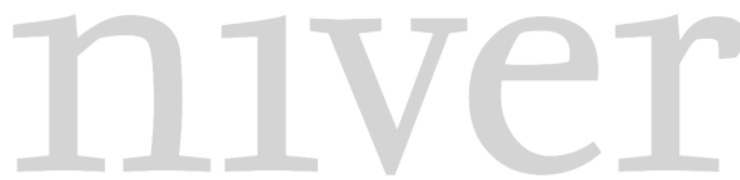

(Article begins on next page)
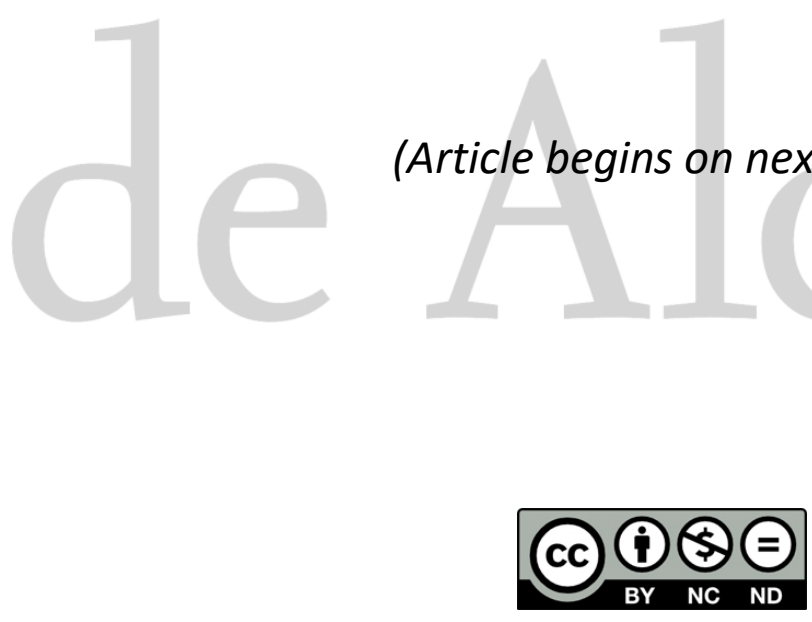

This work is licensed under a

Creative Commons Attribution-NonCommercial-NoDerivatives

4.0 International License. 


\section{Oecologia}

\section{Effective nut dispersal by magpies (Pica pica L.) in a Mediterranean agroecosystem --Manuscript Draft--}

Manuscript Number:

Full Title:

Article Type:

Corresponding Author:

Order of Authors:

Order of Authors:

Response to Reviewers:
OECO-D-16-00918R1

Effective nut dispersal by magpies (Pica pica L.) in a Mediterranean agroecosystem

Plant-microbe-animal interactions - original research

Jorge Castro, Dr

Universidad de Granada

Granada, Granada SPAIN

Jorge Castro, Dr

Mercedes Molina-Morales, Dr.

Alexandro Leverkus, Dr.

Loreto Martínez-Baroja, M.D.

Lorenzo Pérez-Camacho, Dr.

Pedro Villar-Salvador, Dr.

Salvador Rebollo, Dr.

José María Rey-Benayas

December 13, 2016

Dear Dr. Ballaré,

Thank you very much for your email of November 20, 2016 concerning the review of the ms OECO-D-16-00918 "Effective nut dispersal by magpies (Pica pica L.) in a Mediterranean agroecosystem". We thank as well the reviewers for their helpful comments, which have improved the clarity and precision of the manuscript. Virtually all the changes proposed by the reviewers have been incorporated into the attached revised version. We considered the comments carefully when preparing our revision, and provide responses to all of them on the pages below, with detailed explanations of the changes made and their locations in the text. We attach two versions of the revised manuscript, a pdf marking the changes (track changes) and a word documented without tracked changes. Please note that text lines in the responses below refer to the pdf, tracked version.

Reviewer \#1

We greatly appreciate the positive and constructive comments of Dr. Schupp and the annotated copy of the $\mathrm{ms}$ with corrections to improve the English writing. All changes and suggestions indicated by Dr. Schupp have been incorporated into the revised version. We provide a quick summary below:

1. Line 51. We have deleted "effective". Dr. Schupp is right in his question, as there is no measure of effectiveness in this study.

2. Climatic data. Climatic data were obtained from a weather station placed in IFAPA, an agricultural research center with identical environmental conditions located in the same area (Vega de Granada), at $1.5 \mathrm{~km}$ from the study site. This information has been incorporated into the revised version of the $\mathrm{ms}$ for the period of data availability (lines 148-149).

3. Unclear sentence. Nut recovery tended to decrease with increasing distance to the feeder. This information has been clarified in the revised version of the ms (line 322).

4. The likely alternative will be rats... The video-cameras had night vision and recording was made both during day and night times. No rats were recorded removing nuts from the feeders. 
5. About calculation of the qualitative component of effectiveness. We appreciate this indication and we have now added information concerning a quantification of the qualitative component of SDE. For this, we have included in Figure 3 the probability of success for each transitional stage.

Dr. Schupp also enquires about the relationship between nut mass and dispersal distance, and between seed mass and recovery or germination. There was no relationship between nut mass and dispersal distance; this information has been now included in line 300. Note, however, that there is certain pseudoreplication in this analysis as once a nut with a transmitter was found it was re-used several times; we have indicated these details in Data analysis (lines 259-262).

We cannot provide information on the relationship between seed mass and recovery rate. The nuts used to replace the radio-labeled nut were of similar weight. However, we did not mark each nut individually. In any case, we should bear in mind that the nuts dispersed by magpies (with a transmitter inside) were not those they might eventually recover later, as the "original" radio-tagged nut was replaced by one without transmitter. Thus, we do not think that this analysis should be done.

Finally, the same applies to the relationship between nut mass and germination or emergence probability; we did not label each individual nut that was used to replace the radio-tagged nut. In any case, the number of emerged seedlings (2) is too low to conduct this analysis.

6. This is a very long and confusing sentence. Break into multiple smaller sentences. Done.

7. Lines 352-354. I would argue two things here... We agree with Dr. Schupp's comment and acknowledge the confusing message in this part of the ms. To match the text and figures to this concern, we have made the following changes. First, we have rewritten or removed information related to the quantitative component of SDE. Second, we have removed from Figure 3 the vertical legend that was separating the quantitative and qualitative component of SDE. Third, following Dr. Schupp's suggestion, we have calculated the qualitative component of SDE taking as a base line the number of nuts dispersed rather than the number of nuts cached (Figure 3, see also the answer to comment \#5 above). Finally, we have rephrased any detail through the manuscript where a precise specification of the qualitative or quantitative component of SDE had to be done.

8. Lines 364-365 - you are not actually getting an accurate estimate of seed dispersal effectiveness... We appreciate and understand the concern of the reviewer. In this study we provide accurate estimates of the qualitative component of SDE (which is, in fact, a key issue to estimate SDE; e.g. Schupp et al. 2010). However, as noted by the reviewer, we cannot provide an accurate estimate of the quantitative component, even though we demonstrated that the magpies are active walnut dispersers. Consequently, we have made the necessary changes (most of them semantic) to use terminology with accuracy.

Reviewer \#2.

We appreciate the comments of the reviewer and have improved details of the text that, together with the comments of the two other referees, make our specific hypothesis clearer. Nonetheless, contrary to what seems to be the impression of the reviewer, we consider this study to be a relevant contribution in the field of Ecology, particularly for seed dispersal and the interaction between scatter-hoarding birds and nut-producing trees. First, to our knowledge this is the first time that the precise fate of individual nuts dispersed by birds have been monitored until seedling emergence, and we provide key data for improved estimation of the qualitative component of seeddispersal effectiveness. Second, we used a novel methodological approach to conduct our study. In this regard, we disagree that these are "now standard methods for the study of bird scatter-hoarding". To date, only a handful of studies have addressed nut dispersal by corvids using radio-tracking, including the one indicated by the reviewer. In any case, a key additional, linked new approach in our study, beyond the radiotracking method per se, is the further monitoring of individually-tracked seed fates to determine seedling emergence, placing the study in the context of seed dispersal effectiveness. Third, this is the first precise report about the role of magpies as scatterhoarding birds with a potential key role for tree regeneration. Although, as pointed out 
by the reviewer, this could be expected from previous research, this is not a drawback of the study but rather a merit as we put together all previous evidence to generate a hypothesis and design an empirical study to test it. Altogether, we think we are providing novel results that constitute the first report, and will constitute a baseline, to expand our knowledge in a highly relevant plant-animal interaction for forest regeneration. We also explicitly formulated a general, relevant hypothesis and four objectives to corroborate it. Also note that there were more than just "a pair of magpies" dispersing nuts (although we cannot determine the exact number) and that the dispersal distance reached values within what is generally considered to be a longdistance dispersal. In summary, we are confident that our study is novel, and addresses a relevant issue in the field of Ecology.

We have included the study helpfully mentioned by the reviewer (line 107).

Reviewer \#3

We greatly appreciate the positive and constructive comments of the reviewer, including the observations on the novelty and relevance of the study. The reviewer raises as a single major concern the fact that we perform the study in a single location, which might limit statistical inference. Consequently, the recommendation is to treat the results on dispersal effectiveness with more caution, particularly in the Abstract and Discussion section. A similar concern is raised in his/her last comment. We agree with the reviewer that more caution is needed, and we have modified the text accordingly, although we also believe that our data are representative of magpie activity (several individuals were recorded simultaneously in the feeders). We explicitly point out in the Discussion section that our study is based on a single site, and that further studies and replication are needed to ascertain the role of magpies in seed-dispersal effectiveness. We have also modified some sentences of the Abstract according to the reviewer's indications. For example, in lines 18-19 we replace "...that the magpie is an effective scatter-hoarding disperser" by "...that magpies can be an effective scatter-hoarding disperser ...". We hope these clarifications solve the major concern of the reviewer.

Other minor comments:

1. Small grammatical errors. All these typos and grammatical errors have been corrected. Some of them were also detected by Reviewer 1 . We appreciate these kind corrections provided by the reviewers and are confident that now the ms is free of linguistic errors.

2. The first sentence is too long... Done as indicated by the reviewer.

3. Line 46-48: The interjection seems unnecessary. Done as suggested by the reviewer. This was also suggested by Reviewer \#1.

4. Lines 85-94. The information about radio-tracking seems to belong in Methods and not the Introduction. We think that the information here provides a necessary framework to formulate our objectives and hypothesis, and believe it is best included in this section. In any case, we will be happy to reconsider this issue if further requested.

5. Line 143. What are the authors referring with "study area"...? It refers to the Vega of Granada, the geographical area where the study site is located. We understand that there was some confusion with "study area" and "study site" and have rephrased this sentence accordingly. A couple of decades ago the magpies were not present in the "study area", Vega of Granada (and consequently neither at the "study site"), but were common in nearby sites at distances no greater than $20 \mathrm{~km}$. We hope that this is now clear (lines 177-178).

6. Lines 160-165. These sentences can go into caption for Figure 1. Done according to the reviewer's suggestion.

7. Line 235 seems to conflict with lines $249-250 \ldots$ There is no conflict between these lines. Magpies never consumed nuts in the feeders. However, they consumed some nuts within a few hours after dispersal, before the nut with the transmitter was relocated. In those cases, we found the transmitter left on the ground, sometimes with the shell of the nut next to it, or the transmitter still inserted in the shell. Thus, these nuts were not cached but consumed right after dispersal. We have rephrased the sentence in lines $249-250$ of the previous version to eliminate possible confusion, 


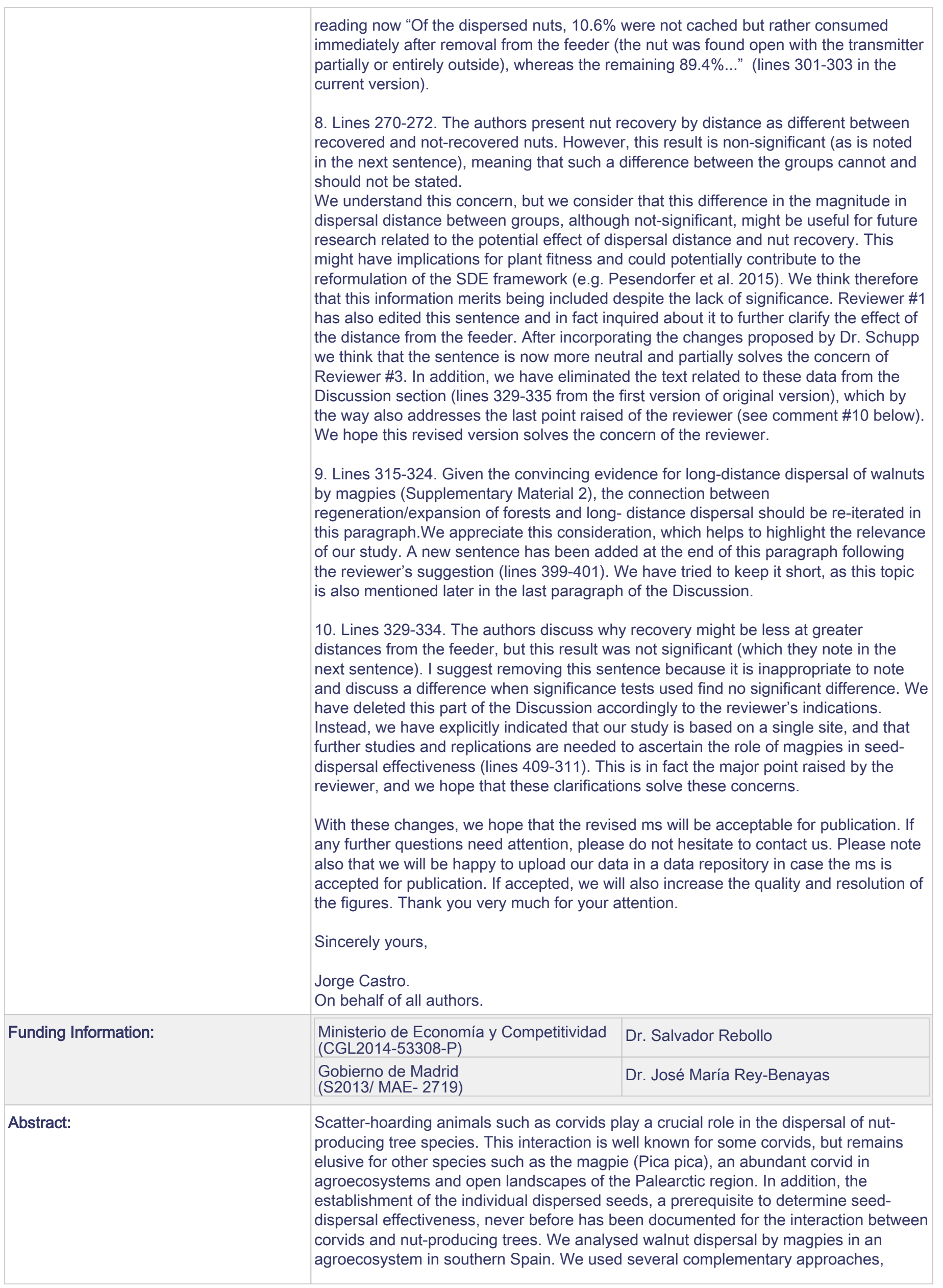


including video-recording of nut removal from feeders, measuring dispersal distance using radio-tracking (with radio transmitters placed inside nuts), and monitoring the fate of dispersed nuts to the time of seedling emergence. Magpies were shown to be highly active as nut dispersers. The dispersal distance averaged $39.6 \pm 4.5 \mathrm{~m}$, with a range from 4.1 to $158.5 \mathrm{~m}$. Some $90 \%$ of the removed walnuts were cached later, and most of these $(98 \%)$ were buried in the soil or hidden under plant material. By the time of seedling emergence, ca. $33 \%$ of nuts still remained in the caching location. Finally, $12 \%$ of the cached nuts germinated, and $4 \%$ yielded an emerged seedling, which allowed the transition to the next regeneration stage. The results demonstrate for the first time that magpies can be an effective scatter-hoarding disperser of a nutproducing tree species, suggesting that this bird species may play a key role for the regeneration and expansion of broadleaf forests in Eurasia. 
December 13, 2016

Dear Dr. Ballaré,

Thank you very much for your email of November 20, 2016 concerning the review of the ms OECO-D-16-00918 "Effective nut dispersal by magpies (Pica pica L.) in a Mediterranean agroecosystem". We thank as well the reviewers for their helpful comments, which have improved the clarity and precision of the manuscript. Virtually all the changes proposed by the reviewers have been incorporated into the attached revised version. We considered the comments carefully when preparing our revision, and provide responses to all of them on the pages below, with detailed explanations of the changes made and their locations in the text. We attach two versions of the revised manuscript, a pdf marking the changes (track changes) and a word documented without tracked changes. Please note that text lines in the responses below refer to the pdf, tracked version.

\section{Reviewer \#1}

We greatly appreciate the positive and constructive comments of Dr. Schupp and the annotated copy of the ms with corrections to improve the English writing. All changes and suggestions indicated by Dr. Schupp have been incorporated into the revised version. We provide a quick summary below:

1. Line 51. We have deleted "effective". Dr. Schupp is right in his question, as there is no measure of effectiveness in this study.

2. Climatic data. Climatic data were obtained from a weather station placed in IFAPA, an agricultural research center with identical environmental conditions located in the same area (Vega de Granada), at $1.5 \mathrm{~km}$ from the study site. This information has been incorporated into the revised version of the $\mathrm{ms}$ for the period of data availability (lines 148-149).

3. Unclear sentence. Nut recovery tended to decrease with increasing distance to the feeder. This information has been clarified in the revised version of the ms (line 322). 
4. The likely alternative will be rats... The video-cameras had night vision and recording was made both during day and night times. No rats were recorded removing nuts from the feeders.

\section{About calculation of the qualitative component of effectiveness. We appreciate} this indication and we have now added information concerning a quantification of the qualitative component of SDE. For this, we have included in Figure 3 the probability of success for each transitional stage.

Dr. Schupp also enquires about the relationship between nut mass and dispersal distance, and between seed mass and recovery or germination. There was no relationship between nut mass and dispersal distance; this information has been now included in line 300. Note, however, that there is certain pseudoreplication in this analysis as once a nut with a transmitter was found it was re-used several times; we have indicated these details in Data analysis (lines 259-262).

We cannot provide information on the relationship between seed mass and recovery rate. The nuts used to replace the radio-labeled nut were of similar weight. However, we did not mark each nut individually. In any case, we should bear in mind that the nuts dispersed by magpies (with a transmitter inside) were not those they might eventually recover later, as the "original" radio-tagged nut was replaced by one without transmitter. Thus, we do not think that this analysis should be done.

Finally, the same applies to the relationship between nut mass and germination or emergence probability; we did not label each individual nut that was used to replace the radio-tagged nut. In any case, the number of emerged seedlings (2) is too low to conduct this analysis.

\section{This is a very long and confusing sentence. Break into multiple smaller sentences.}

Done.

7. Lines 352-354. I would argue two things here... We agree with Dr. Schupp's comment and acknowledge the confusing message in this part of the ms. To match the text and figures to this concern, we have made the following changes. First, we have rewritten or removed information related to the quantitative component of SDE. Second, we have removed from Figure 3 the vertical legend that was separating the 
quantitative and qualitative component of SDE. Third, following Dr. Schupp's suggestion, we have calculated the qualitative component of SDE taking as a base line the number of nuts dispersed rather than the number of nuts cached (Figure 3, see also the answer to comment \#5 above). Finally, we have rephrased any detail through the manuscript where a precise specification of the qualitative or quantitative component of SDE had to be done.

\section{Lines 364-365 - you are not actually getting an accurate estimate of seed}

dispersal effectiveness... We appreciate and understand the concern of the reviewer. In this study we provide accurate estimates of the qualitative component of SDE (which is, in fact, a key issue to estimate SDE; e.g. Schupp et al. 2010). However, as noted by the reviewer, we cannot provide an accurate estimate of the quantitative component, even though we demonstrated that the magpies are active walnut dispersers. Consequently, we have made the necessary changes (most of them semantic) to use terminology with accuracy.

\section{Reviewer \#2.}

We appreciate the comments of the reviewer and have improved details of the text that, together with the comments of the two other referees, make our specific hypothesis clearer. Nonetheless, contrary to what seems to be the impression of the reviewer, we consider this study to be a relevant contribution in the field of Ecology, particularly for seed dispersal and the interaction between scatter-hoarding birds and nut-producing trees. First, to our knowledge this is the first time that the precise fate of individual nuts dispersed by birds have been monitored until seedling emergence, and we provide key data for improved estimation of the qualitative component of seed-dispersal effectiveness. Second, we used a novel methodological approach to conduct our study. In this regard, we disagree that these are "now standard methods for the study of bird scatter-hoarding". To date, only a handful of studies have addressed nut dispersal by corvids using radio-tracking, including the one indicated by the reviewer. In any case, a key additional, linked new approach in our study, beyond the radio-tracking method per $s e$, is the further monitoring of individually-tracked seed fates to determine seedling emergence, placing the study in the context of seed dispersal effectiveness. Third, this is the first precise report about the role of magpies as scatter-hoarding birds with a potential key role for tree regeneration. Although, as pointed out by the reviewer, this 
could be expected from previous research, this is not a drawback of the study but rather a merit as we put together all previous evidence to generate a hypothesis and design an empirical study to test it. Altogether, we think we are providing novel results that constitute the first report, and will constitute a baseline, to expand our knowledge in a highly relevant plant-animal interaction for forest regeneration. We also explicitly formulated a general, relevant hypothesis and four objectives to corroborate it. Also note that there were more than just "a pair of magpies" dispersing nuts (although we cannot determine the exact number) and that the dispersal distance reached values within what is generally considered to be a long-distance dispersal. In summary, we are confident that our study is novel, and addresses a relevant issue in the field of Ecology.

We have included the study helpfully mentioned by the reviewer (line 107).

\section{Reviewer \#3}

We greatly appreciate the positive and constructive comments of the reviewer, including the observations on the novelty and relevance of the study. The reviewer raises as a single major concern the fact that we perform the study in a single location, which might limit statistical inference. Consequently, the recommendation is to treat the results on dispersal effectiveness with more caution, particularly in the Abstract and Discussion section. A similar concern is raised in his/her last comment. We agree with the reviewer that more caution is needed, and we have modified the text accordingly, although we also believe that our data are representative of magpie activity (several individuals were recorded simultaneously in the feeders). We explicitly point out in the Discussion section that our study is based on a single site, and that further studies and replication are needed to ascertain the role of magpies in seed-dispersal effectiveness. We have also modified some sentences of the Abstract according to the reviewer's indications. For example, in lines 18-19 we replace “...that the magpie is an effective scatter-hoarding disperser” by “...that magpies can be an effective scatter-hoarding disperser ...". We hope these clarifications solve the major concern of the reviewer.

Other minor comments:

1. Small grammatical errors. All these typos and grammatical errors have been corrected. Some of them were also detected by Reviewer 1. We appreciate these kind corrections provided by the reviewers and are confident that now the ms is free of linguistic errors. 
2. The first sentence is too long... Done as indicated by the reviewer.

3. Line 46-48: The interjection seems unnecessary. Done as suggested by the reviewer. This was also suggested by Reviewer \#1.

\section{Lines 85-94. The information about radio-tracking seems to belong in Methods} and not the Introduction. We think that the information here provides a necessary framework to formulate our objectives and hypothesis, and believe it is best included in this section. In any case, we will be happy to reconsider this issue if further requested.

5. Line 143. What are the authors referring with "study area"...? It refers to the Vega of Granada, the geographical area where the study site is located. We understand that there was some confusion with "study area" and "study site" and have rephrased this sentence accordingly. A couple of decades ago the magpies were not present in the "study area", Vega of Granada (and consequently neither at the "study site"), but were common in nearby sites at distances no greater than $20 \mathrm{~km}$. We hope that this is now clear (lines 177-178).

6. Lines 160-165. These sentences can go into caption for Figure 1. Done according to the reviewer's suggestion.

7. Line 235 seems to conflict with lines $249-250 .$. . There is no conflict between these lines. Magpies never consumed nuts in the feeders. However, they consumed some nuts within a few hours after dispersal, before the nut with the transmitter was relocated. In those cases, we found the transmitter left on the ground, sometimes with the shell of the nut next to it, or the transmitter still inserted in the shell. Thus, these nuts were not cached but consumed right after dispersal. We have rephrased the sentence in lines 249250 of the previous version to eliminate possible confusion, reading now "Of the dispersed nuts, $10.6 \%$ were not cached but rather consumed immediately after removal from the feeder (the nut was found open with the transmitter partially or entirely outside), whereas the remaining 89.4\%...” (lines 301-303 in the current version). 


\section{Lines 270-272. The authors present nut recovery by distance as different}

between recovered and not-recovered nuts. However, this result is non-significant (as is noted in the next sentence), meaning that such a difference between the groups cannot and should not be stated.

We understand this concern, but we consider that this difference in the magnitude in dispersal distance between groups, although not-significant, might be useful for future research related to the potential effect of dispersal distance and nut recovery. This might have implications for plant fitness and could potentially contribute to the reformulation of the SDE framework (e.g. Pesendorfer et al. 2015). We think therefore that this information merits being included despite the lack of significance. Reviewer \#1 has also edited this sentence and in fact inquired about it to further clarify the effect of the distance from the feeder. After incorporating the changes proposed by Dr. Schupp we think that the sentence is now more neutral and partially solves the concern of Reviewer \#3. In addition, we have eliminated the text related to these data from the Discussion section (lines 329-335 from the first version of original version), which by the way also addresses the last point raised of the reviewer (see comment \#10 below). We hope this revised version solves the concern of the reviewer.

\section{Lines 315-324. Given the convincing evidence for long-distance dispersal of} walnuts by magpies (Supplementary Material 2), the connection between regeneration/expansion of forests and long- distance dispersal should be reiterated in this paragraph. We appreciate this consideration, which helps to highlight the relevance of our study. A new sentence has been added at the end of this paragraph following the reviewer's suggestion (lines 399-401). We have tried to keep it short, as this topic is also mentioned later in the last paragraph of the Discussion.

\section{Lines 329-334. The authors discuss why recovery might be less at greater} distances from the feeder, but this result was not significant (which they note in the next sentence). I suggest removing this sentence because it is inappropriate to note and discuss a difference when significance tests used find no significant difference. We have deleted this part of the Discussion accordingly to the reviewer's indications. Instead, we have explicitly indicated that our study is based on a single site, and that further studies and replications are needed to ascertain the role of magpies in seed- 
dispersal effectiveness (lines 409-311). This is in fact the major point raised by the reviewer, and we hope that these clarifications solve these concerns.

With these changes, we hope that the revised ms will be acceptable for publication. If any further questions need attention, please do not hesitate to contact us. Please note also that we will be happy to upload our data in a data repository in case the $\mathrm{ms}$ is accepted for publication. If accepted, we will also increase the quality and resolution of the figures. Thank you very much for your attention.

Sincerely yours,

Jorge Castro.

On behalf of all authors. 


\title{
Effective nut dispersal by magpies (Pica pica L.) in a Mediterranean
} agroecosystem

\author{
Jorge Castro $^{1 *}$, Mercedes Molina-Morales ${ }^{2}$, Alexandro B. Leverkus ${ }^{1}$, Loreto Martínez- \\ Baroja $^{3}$, Lorenzo Pérez-Camacho ${ }^{3}$, Pedro Villar-Salvador ${ }^{3}$, Salvador Rebollo $^{3}$ and José \\ M. Rey-Benayas ${ }^{3}$
}

${ }^{1}$ Departamento de Ecología, Facultad de Ciencias, Universidad de Granada, E-18071 Granada, Spain.

${ }^{2}$ Departamento de Zoología, Facultad de Ciencias, Universidad de Granada, E-18071 Granada, Spain.

${ }^{3}$ Grupo de Investigación “Ecología y Restauración Forestal” FORECO. Departamento de Ciencias de la Vida, UD Ecología, Edificio de Ciencias, Universidad de Alcalá, 28805 Alcalá de Henares, Spain

*Author for Correspondence. Email: jorge@ugr.es

Author Contributions: JC, LPC, PVS, SR and JMRB conceived and designed the experiments. JC, MMM, AL and LMB performed the field work. JC, MMM and AL performed statistical analyses. JC wrote the first draft of the ms; all authors provided editorial advice. 


\section{Abstract}

2 Scatter-hoarding animals such as corvids play a crucial role in the dispersal of nut-

3 producing tree species. This interaction is well known for some corvids, but remains

4 elusive for other species such as the magpie (Pica pica), an abundant corvid in

5 agroecosystems and open landscapes of the Palearctic region. In addition, the

6 establishment of the individual dispersed seeds, a prerequisite to determine seed-

7 dispersal effectiveness, never before has been documented for the interaction between

8 corvids and nut-producing trees. We analysed walnut dispersal by magpies in an

9 agroecosystem in southern Spain. We used several complementary approaches,

10 including video-recording of nut removal from feeders, measuring dispersal distance

11 using radio-tracking (with radio transmitters placed inside nuts), and monitoring the fate

12 of dispersed nuts to the time of seedling emergence. Magpies were shown to be highly

13 active as nut dispersers. The dispersal distance averaged $39.6 \pm 4.5 \mathrm{~m}$, with a range from

144.1 to $158.5 \mathrm{~m}$. Some $90 \%$ of the removed walnuts were cached later, and most of these

$15(98 \%)$ were buried in the soil or hidden under plant material. By the time of seedling

16 emergence, ca. $33 \%$ of nuts still remained in the caching location. Finally, $12 \%$ of the

17 cached nuts germinated, and $4 \%$ yielded an emerged seedling, which allowed the

18 transition to the next regeneration stage. The results demonstrate for the first time that

19 magpies can be an effective scatter-hoarding disperser of a nut-producing tree species,

20 suggesting that this bird species may play a key role for the regeneration and expansion

21 of broadleaf forests in Eurasia.

23 Key words: Corvidae, forest regeneration, Juglans, radio-tracking, scatter-hoarding,

24 seed caching, seed dispersal effectiveness 
INTRODUCTION

Seed dispersal of large-seeded species of paramount relevance in the context of temperate forests is largely ascribed to a plant-animal interaction in which a vertebrate vector is responsible for direct seed transport (Vander Wall 1990; Johnson et al. 1997; Pesendorfer et al. 2016). Several bird species from the Corvidae family are among the most active dispersers for these trees, acting as scatter-hoarding animals that cache seeds in a large number of locations across the landscape for later consumption, disperse a very large number of seeds, and usually cover distances exceeding hundreds or even thousands of meters (Bossema 1979; Darley-Hill and Johnson 1981; Lenda et al. 2012; Pesendorfer et al. 2016). A fraction of the seeds may remain un-recovered, providing the opportunity for seed germination and tree recruitment (Vander Wall 1990; Pesendorfer et al. 2016). In fact, the interaction between corvids and many tree species from the Fagaceae or Juglandaceae plant families is considered a key mutualistic relationship for the regeneration, colonization, and expansion of forests in the Northern Hemisphere, helping to explain the post-glacial migration and current distribution of temperate forests (Johnson and Webb III 1989; Johnson et al. 1997; Vander Wall 1990; Mosandl and Kleinert 1998; Pesendorfer et al. 2016).

The role of corvids in the transport of nuts has been noted since ancient times (e.g. Aristotle and Theophrastus; Thanos 1994), and for decades has been intensively studied in several species throughout the Holarctic region (e.g. Grinnell 1936; Richards 1958; Bossema 1979; Cristol 2005; Pesendorfer et al. 2016 [and references therein]). In the case of North America, at least seven species have been described as dispersers of nuts from Fagaceae or Juglandaceae species (Cristol 2005; Pesendorfer et al. 2016). However, the dispersal of large nuts such as acorns and walnuts by corvids in Eurasia is 
ascribed mostly to a single species, the European jay (Garrulus glandarius L.)

52 (Bossema 1979; Pesendorfer et al. 2016), and to a much lesser extent to the rook (Corvus frugilegus L.) (Waite 1985; Källender 2007; Lenda et al. 2012). Knowledge of the role of other corvids in the regeneration of these tree species in the Palearctic is almost negligible. In particular, the black-billed magpie (Pica pica L., hereafter referred to as "magpie"), a common corvid in Eurasia, is considered to have little relevance for tree dispersal, as it is assumed to preferentially cache perishable food, while caching few nuts within short distances, and with a recovery time of only a few days (Henty 1975; Waite 1985; Birkhead 1991).

Several pieces of evidence, however, suggest that magpies might be noteworthy vectors in nut dispersal. It is well established that magpies cache food items (Henty 1975; Clarkson et al. 1986; Birkhead 1991), have the capacity to recall cache locations (Zinkivskay et al. 2008; Feenders and Smulders 2011) and have a well-developed hippocampus (Healy and Krebs 1992; Brodin and Lundberg 2003), a brain region linked to spatial memory and food-storing behaviour. Magpies have also been suggested to be the most likely dispersers of almond trees in agroforestry systems (Homet-Gutiérrez et al. 2015), and reports on acorn dispersal, although very scant, are available (Birkhead 1991). In short, several clues support the idea that magpies might have an influential role in nut dispersal for Eurasian tree species. However, to date, the magnitude of nut dispersal and recovery rate for this bird have never been documented. Although many studies have addressed the dispersal of nut-producing trees by corvids (e.g. review by Pesendorfer et al. 2016), a gap in knowledge persists concerning the implications of this mutualistic interaction for forest regeneration. Studies reporting

74 a link between the vector and the plant are based mostly on evidence arising from synchronic observations of dispersal and seedling-recruitment patterns (e.g. Mosandl 
and Kleinert 1998; Gómez 2003; Hougner et al. 2006; Castro et al. 2012; Lenda et al.

77 2012; Puerta-Piñero et al. 2012). This procedure has demonstrated beyond a doubt that the corvids are major vectors for nut dispersal. However, a fine-grained quantification of the effect of animal seed-dispersal vectors requires precise knowledge concerning the

80 fate of the dispersed seed, an aspect seldom addressed in studies of seed dispersal

81 (Schupp and Fuentes 1995; Schupp et al. 2010) and, as far as we know, never addressed

82 for the interaction between corvids and nut-producing tree species. The use of radiotracking with small transmitters embedded in the seed is a recent method to study nut dispersal (e.g. Pons and Pausas 2007; Tamura and Hayashi 2008; Morán-López et al. 2015). By replacing the transmitter-containing nut after dispersal by another nonmanipulated nut able to germinate and continue with the recruitment processes, we might be able to monitor the magnitude of effective seed dispersal. Although this method could still underestimate the probability of recruitment in case the dispersed nuts are re-cached, it has the potential to provide a more accurate measure of the qualitative component of seed-dispersal effectiveness (sensu Schupp et al. 2010) and a more comprehensive picture of the role of corvids in the recruitment of nut-producing tree species.

In this study, we analyse the activity of magpies, a common corvid in open landscapes and agroforestry systems throughout Eurasia, in the dispersal of the common walnut (Juglans regia L.). Nut removal, dispersal distance, cache location, and seedling emergence were precisely monitored, providing the necessary framework to analyse the

97 seed-dispersal effectiveness mediated by a vertebrate vector. Given the already known scatter-hoarding behaviour of magpies and their capacity to remember caching sites, together with observations made under field conditions supporting magpie nut dispersal

100 (Birkhead 1991; Omat et al. 2015, author's personal observations), we hypothesise that 
101 magpies are effective nut dispersers. Four specific questions were posed: 1) Do magpies

102 disperse walnuts in the study area? 2) What are the characteristics of dispersal events in

103 terms of habitat selection, caching type, and dispersal distance? 3) What is the recovery

104 rate of cached nuts? And 4) what are the germination and emergence rates of

105 unrecovered nuts? The response to these questions will allow us to determine an

106 accurate value of the qualitative component of seed-dispersal effectiveness and the role

107 of magpies as dispersers for a nut-producing tree.

108

MATERIALS AND METHODS

110 1. Study site and natural history of the system

111 The study was conducted in an agroforestry system located in the "Vega de Granada"

112 (SE Spain, $37^{\circ} 10^{\prime} 03.43^{\prime \prime} \mathrm{N}, 3^{\circ} 36^{\prime} 57.80^{\prime \prime} \mathrm{W}$ ), a flat and irrigated agricultural area of

113 small-sized farms located at ca. $650 \mathrm{~m}$ a.s.l. The area is used mainly for crop

114 production, mostly vegetables, maize, tree plantations, and pasture. The soil is deep and

115 loamy, and the climate is Mediterranean-type, with hot, dry summers and mild winters.

116 The mean annual rainfall is $394 \pm 71 \mathrm{~L} \mathrm{~m}^{2} \mathrm{y}^{-1}$ and the mean temperature $15.3 \pm 0.1{ }^{\circ} \mathrm{C}$

117 (period 2006-2015, based upon climatic data from a meteorological station located at

118 IFAPA Research Field Station, $1.5 \mathrm{~km}$ from the study site). Common walnut (Juglans

119 regia; target plant species of this study) is traditionally grown in the farms of the area

120 (presumably since Roman times; Buxó 1997), usually as scattered trees close to houses.

121 The study site was a 1.8-ha farm (hereafter referred to as "core site") plus

122 surrounding fields where nut dispersal could be registered with radio-tracking. The core

123 site, which is used mostly for research purposes, is divided into three main areas

124 (habitats, hereafter), namely 1) a broadleaf stand, 2) a pine stand, and 3) cropland (Fig.

125 1). The broadleaf habitat is a $7000-\mathrm{m}^{2}$ mixed tree plantation of poplar (Populus $\times$ 
127 Juglans regia MJ 209xRa) with an even number of individuals, all trees being evenly 128 spaced at a planting density of 400 individuals ha $^{-1}$. Tree diameter at breast height in

129 October 2015 was $27.6 \pm 0.3 \mathrm{~cm}$ for poplar and $9.6 \pm 0.2 \mathrm{~cm}$ for hybrid walnut. The pine

130 habitat consisted of $2000 \mathrm{~m}^{2}$ of Aleppo pine saplings (Pinus halepensis Mill.), evenly

131 spaced at a density of 1200 individuals $\mathrm{ha}^{-1}$. Saplings had a height of $1.95 \pm 0.04 \mathrm{~m}$ by

132 October 2015, with lower branches touching the ground. The cropland habitat covers

133 the rest of the core site area and is used for vegetable production (Fig. 1). It also

134 contains some scattered fruit trees (3-6 m tall) such as plums, apples, pears,

135 persimmons, fig trees and peaches, for a total of 34 individuals. The three habitat types

136 were ploughed in late August 2015, one week before the start of this study.

137 The black-billed magpie is a corvid widely distributed across the Palearctic and

138 is the most abundant corvid in southern Europe (Cramp and Perrins 1994; Martí and Del

139 Moral 2003). It is particularly abundant in agroecosystems and open landscapes where

140 other nut-dispersing corvids such as the Europen jay are usually absent (Martí and Del

141 Moral 2003; Martínez 2011). The magpie is a common species in the Iberian Peninsula,

142 but was absent in the study area until some years ago despite being common in nearby

143 areas at distances of ca. $20 \mathrm{~km}$. Regular bird sampling in the study area since 1985

144 (J.C.; unpublished data) showed that they appeared in low numbers (occasional

145 individuals) in 2002 and started nesting in 2008. Their population has steadily increased

146 since then, currently being a common breeding bird in the area. Coinciding with its

147 arrival to the study site, the emergence of walnut seedlings in the fields became evident.

148 In 2012 we made preliminary observations and confirmed that magpies were dispersing

149 nuts picked directly from J. regia trees of the area. These observations were not 
150 methodical, but they led us to formulate the hypotheses and sampling design to conduct

151 this study.

\section{Sampling of the magpie-walnut interaction}

154 We studied the interaction between magpie and walnut by using three complementary

155 approaches: 1) monitoring the removal of non radio-tagged nuts offered in feeders, 2)

156 monitoring the removal and dispersal distance of radio-tagged nuts offered in feeders,

157 and 3) monitoring post-dispersal recovery rate and seedling recruitment for nuts that

158 replaced the radio-tagged nuts. Nut dispersal was sampled in all cases within the period

159 of natural nut ripening and dispersal in the study area. The coordinates of all dispersed

160 nuts and feeders were marked with a GPS, which allowed dispersal distances to be

161 calculated using Quantum GIS. For the core site, we also constructed an ortho-photo

162 from 5-cm/pixel-resolution photos (Fig. 1).

163 The removal of non radio-tagged nuts placed in feeders was monitored from

164 September 5 to October 26, 2015 (see Fig. S1 for feeder details). A total of 165 nuts

165 were offered in bunches of 20 (occasionally 10 or 5; Table 1), and a video camera with

166 a continuous recording system and day and night vision was placed at ca. $1.5 \mathrm{~m}$ from

167 the nuts (Miniature Motion Activated DVR Resolution SSC-758HQ, coupled with Led

168 Color Cameras SSC-56C36; Advance Security, Belleville, Illinois, USA). Also, we

169 conducted non-systematic direct observations from a hide. A fraction of the nuts (120)

170 were weighed before placing them in the feeders, and they were identified with a

171 number on the shell using waterproof, permanent ink. Overall, this procedure was

172 chosen as an initial method to test nut removal by magpies (i.e. before using radio

173 transmitters) to reduce nut manipulation and potential distrust by magpies. It also

174 allowed us to ascertain the disperser's identity and activity. 
176 October 25 to December 12, 2015. For this, a radio transmitter (PIP2 Tag Ag392;

177 Biotrack, Wareham, Dorset, UK; weight: $2.2 \mathrm{~g}$; mean life span: 3 months) was placed

178 inside the nut, which allowed us to relocate dispersed nuts and to measure exact

179 dispersal distances. Nut removal was also video-recorded with a movement-sensitive

180 system (Moultrie M-990i; Moultrie Products, Alabama, USA) as well as with day and

181 night vision. For each sample, the walnut shell was split open along the suture, a portion

182 of the kernel of similar weight to the transmitter was excised, the transmitter with its

183 antenna rolled up was placed inside the nut, and then the two halves of the nut were

184 glued together with Loctite ${ }^{\circledR}$ (Supplementary Material 1, Fig. S2). Five transmitter-

185 containing nuts were used, either in a single feeder or divided into groups of 2 and 3

186 nuts in the two feeders simultaneously. Eventually, we noted that magpies refused to

187 pick some radio-tagged nuts from the feeders, which might have been due to desiccation

188 or to any other cue that we could not identify. In those cases we changed the transmitter

189 to another nut. Once removed from the feeders, the nuts with the radio-transmitter were

190 located (usually within a few hours after dispersal) with the help of a radio-tracking

191 receiver with a unidirectional Yagi antenna (Biotrack, Wareham, Dorset, UK) plus a

192 hand-held metal detector (White's Auto-Scan Personal Search Detector, Tulsa,

193 Oklahoma, USA) for exact location of the nut/transmitter, which is particularly

194 necessary for buried nuts. The caching characteristics were categorized as: 1)

195 Superficial, nuts left visible, on the soil surface; 2) Buried, nuts buried in bare soil; and

196 3) Under plant material, nuts hidden below leaf litter or below leaves of live vegetation,

197 the latter including forbs, grasses, vegetables or the pine branches that were touching

198 the ground in the pine habitat. 
200 with a transmitter was located, the nut was placed back in the feeders, and a non-

201 manipulated nut of similar weight was placed in the same location. The point where the

202 nut was found was marked with a wooden stake (12 cm x $9 \mathrm{~mm}$ x $9 \mathrm{~mm}) 50 \mathrm{~cm}$ away

203 from the nut, and a small metal rod was placed under the nut to facilitate later relocation

204 with the metal detector. Approximately 6 months later (from 5 to 24 May 2016),

205 coinciding with the period of seedling emergence in the study area, we sampled the

206 status of all those nuts, considering as categories: absent (assigned as recovered), non-

207 germinated, germinated, and emerged seedling. In the case of emerged seedlings we

208 also noted seedling height.

210 4. Data analyses

211 We analysed differences in the weight among removed and non-removed nuts from the

212 feeders with a one-way ANOVA. The effect of nut weight on dispersal distance was

213 assessed with a linear mixed model in the lme R package (Pinheiro et al. 2016), using

214 nut as a random effect because the same transmitter-containing nuts were placed in the

215 feeders several times. Differences in caching types were analysed with contingency

216 tests, and the effect of caching type on recovery rates with a glm with a binomial

217 distribution. The effect of habitat type and distance from the feeder on nut dispersal was

218 analysed with spatial statistics. This analysis was restricted to the core site given that in

219 this area the habitats persisted through the study period, whereas outside the core site

220 the crops changed from September to December, precluding definition of permanent

221 habitats. For this, we fitted point process models with the spatstat R package (Baddeley

$222 \&$ Turner 2005). The models considered a non-homogeneous Poisson process, with the

223 density of dispersed nuts within the core site depending on two spatial covariates: 
224 habitat type (broadleaf, pine or farmland) and a map of the distance of each 1 x $1 \mathrm{~m}$

225 pixel to the feeder. The performance of this model was assessed through likelihood ratio 226 tests during model simplification. This procedure was performed for the nuts dispersed

227 from Feeder 1, as the number of nuts from Feeder 2 was insufficient to perform this 228 analysis. Analyses were performed with R version 3.1.1 in all cases (R Core Team 229 2014).

\section{RESULTS}

\section{Nut removal from feeders}

233 A total of 193 nuts were removed from feeders, including nuts with and without

234 transmitters (68 and 125, respectively; Table 1). In 98\% of the cases, the disperser was

235 video-recorded or directly observed from the hide, and it was a magpie in all cases.

236 Magpies in no case consumed nuts in the feeders, and the number of nuts removed was

237 one in all dispersal events. The number of magpies observed simultaneously in the

238 feeders ranged from 1 to 5 . Removed nuts were heavier $(9.44 \pm 0.17 \mathrm{~g})$ than non-

239 removed nuts $(8.67 \pm 0.32 \mathrm{~g} ; \mathrm{F}=4.47$, d.f. $=1,118, \mathrm{p}=0.037)$. Overall, magpies showed a

240 high activity, and were able to remove all or most of the nuts within a few hours (Table $2411)$.

\section{Dispersal distance and caching characteristics}

244 Dispersal distance was measured for 66 radio-tagged nuts. Mean dispersal distance was $24539.6 \pm 4.5 \mathrm{~m}$, with a range of 4.1 to $158.5 \mathrm{~m}$ (Fig. 2a). Two nuts containing transmitters 246 were not found despite thorough searching up to a distance of at least $300 \mathrm{~m}$ from the 247 core site (not considered for analyses), and they were likely carried long-distances based 
on video-camera recordings of these nuts (see Supplementary Material 2 for a video of

249 one of the cases). Nut weight did not affect dispersal distance (L.Ratio $=0.58, \mathrm{p}=0.45$ ).

250 Of the dispersed nuts, $10.6 \%$ were not cached but rather consumed immediately

251 after removal from the feeder (the nut was found open with the transmitter partially or

252 entirely outside), whereas the remaining $89.4 \%$ (59 nuts) were cached. Of those, $55.9 \%$

253 were buried in the soil (at 1-3 cm depth in all cases), $42.4 \%$ cached under plant material,

254 and only one $(1.7 \%)$ was left on the ground surface $($ Chisq $=25.36, \mathrm{df}=2, \mathrm{p}<0.001)$.

255 In all cases the nuts were cached individually. Two of the nuts cached under plant

256 material were located on a roof, although still hidden below litter.

257 The point process models did not show a significant effect of habitat type on the

258 density of dispersed nuts ( $\Delta \mathrm{Dev}=0.94, \mathrm{df}=2, \mathrm{p}=0.63)$, but they showed a significant

259 negative effect of distance from the feeder ( $\Delta$ Dev $=114.62$, df $=1, p<0.001$; Fig. $2 b)$.

260

261

3. Nut recovery and seedling recruitment

262 By May 2016 we were able to determine the fate of 49 of the 59 cached radio-tracked

263 nuts; the remaining 10 nuts were either lost (four sampling points within the core site

264 could not be relocated) or dispersed outside the core site, where the ground was tilled

265 before the time of sampling (thus provoking the loss of the sampling point). Of these 49

266 nuts, $67.3 \%$ were recovered, $20.4 \%$ did not germinate, $12.2 \%$ germinated (including

267 emerged ones), and $4.1 \%$ produced an emerged seedling (Fig. 3).

268 Nut recovery was $73.5 \%$ in the cropland habitat, $57.1 \%$ in the broadleaf habitat,

269 and $33.3 \%$ in the pine habitat, although there were no significant differences among

270 habitat types $(\mathrm{ChiSq}=3.79$, d.f. $=2, \mathrm{p}=0.15)$. Nut recovery tended to decrease with

271 increasing distance to the feeder, with non-recovered nuts being at an average distance 
272 of $37.2 \pm 6.2 \mathrm{~m}$ from the feeder vs $27.5 \pm 4.3 \mathrm{~m}$ for the recovered nuts. Nonetheless, this

273 trend was not significant (logistic regression, $\mathrm{ChiSq}=1.61$, d.f. $=1, \mathrm{p}=0.20$ ).

274 We could not unequivocally determine the animal that removed the cached nuts,

275 but we often observed magpies recovering nuts in the study area, and found a large

276 number of nuts consumed and opened in two valves as is characteristic in magpies

277 (Homet-Guitérrez et al. 2015; author's personal observation). No other animal was

278 directly observed removing the nuts dispersed by the magpies. Recovery activity

279 spanned the entire study period, and we observed magpies consuming recovered nuts

280 until early May 2016.

282 DISCUSSION

283 In this study, the magpie, an abundant corvid in Eurasian agroecosystems and open

284 landscapes, proved to be an effective disperser of a large-seeded species, moving a large

285 number of walnuts over dispersal distances that reached $158 \mathrm{~m}$. Furthermore, a fraction

286 of the nuts was not recovered after caching and resulted in effective early seedling

287 recruitment. Magpies had previously been suggested as dispersers for nut-producing

288 tree species such as oaks (Birkhead 1991) or almond trees (Homet-Gutiérrez et al.

289 2015), but this interaction had never been demonstrated or measured in the context of

290 plant recruitment. Our study contributes to the understanding of the role of scatter-

291 hoarding corvids in the regeneration of Eurasian forests, and provides for the first time

292 precise information of the qualitative component of seed-dispersal effectiveness for the

293 interaction between birds and nut-producing trees.

Nut dispersal 
296 Most of the nuts that were offered in the feeders were quickly dispersed and cached, and

297 only a small fraction (ca. 10\%) was consumed just after removal. This behaviour is

298 typical in scatter-hoarding animals, which display vigorous dispersal activity when the

299 resource is abundant presumably in order to accumulate as much of it as possible during

300 the short period of availability (Clarkson et al. 1986; Vander Wall 2001). After nut

301 removal from feeders or trees, magpies also displayed a behaviour similar to that of

302 other corvids (Bossema 1979; Cristol 2005). On arriving to a place to hide the nut, they

303 wandered for a few seconds as if selecting the most preferable site, presumably

304 checking for potential competitors that could steal the cached nut. In fact, in some cases

305 they flew away with the nut and searched for another site. To cache the nut, they pushed

306 it with the beak, sometimes hammering on it to bury it in the soil, and then they covered

307 the site with soil or litter in such a way that the exact caching point became undetectable

308 to the human eye (see Birkhead 1991 for a description of similar behaviour). In

309 addition, the majority of the cached nuts were buried in the soil or hidden under plant

310 material, both being microhabitats that may favour seed germination and seedling

311 recruitment by reducing the risk of predation and desiccation (Bossema 1979; Vander

312 Wall 1990, 2001; Gómez 2004). Furthermore, magpies preferred heavier nuts, therefore

313 favouring a trait (large seed mass) that may enhances seedling establishment (Castro et

314 al. 2006).

315 The observed dispersal distances lie within the lower range described for the

316 rook, a corvid with a documented role in walnut dispersal (Lenda et al. 2012).

317 Nonetheless, the body mass of the rook (around $500 \mathrm{~g}$ ) is much larger than the mass of

318 the magpie (around $200 \mathrm{~g}$ ). In addition, two of the transmitters were lost, perhaps as a

319 consequence of long-distance dispersal. In fact, we observed several events in which a

320 magpie flying from a feeder with a nut was lost in the distance, likely far beyond the 
maximum dispersal distance recorded (Supplementary Material 2). In any case, $7.3 \%$ of

322 the nuts were dispersed beyond $100 \mathrm{~m}$, a distance and proportion great enough to

323 support the contention that magpies can act as long-distance seed dispersers (Cain et al.

324 2000). Thus, magpies can play a relevant role in the expansion of nut-producing trees

325 into new areas, a key step for the regeneration of the temperate forest (Pesendorfer et al.

326 2015).

327 The seed rain generated also supports the idea that magpies are effective

328 dispersers in agroecosystems and agroforestry mosaics, since nuts were invariably

329 cached alone, one by one, and were widely distributed throughout different habitats of

330 the landscape. Some consequences of the spatial structuring of the seed rain for plant

331 recruitment also seems plausible, as shown by the facts that caching density decreased

332 with distance from the source (as it is ultimately expected in a cost-benefit trade-off;

333 Clarkson et al. 1986), or that there were significant differences in caching

334 characteristics. Nonetheless, our results are based in a single study site, which precludes

335 generalization of patterns. Further studies including more study areas and larger sample

336 size would be necessary to ascertain the relationship between habitat characteristics,

337 dispersal distance, and its potential implication for effective long-distance dispersal.

338 Radio-tracking, combined with the monitoring of the fate of seeds that replace the

339 dispersed, radio-tagged seed, has proved to be an appropriate method to answer these

340 questions.

342 Post-dispersal nut recovery and seed dispersal effectiveness

343 Radio-tracking also allowed us to obtain accurate estimates of nut recovery, which

344 reached $67 \%$ ca. 8 months after dispersal. Magpies were the only animals observed

345 recovering the nuts. Rodent pilfering of part of the nuts cannot be ruled out, but these 
346 animals appear to play a minor role in this system, as throughout the study period we

347 found only three nuts with marks of chewing by rodents on the shell vs. a high number

348 (not recorded) of nuts opened in two halves as magpies do. We cannot discount

349 pilfering by other magpies, either, or the re-caching by the original magpie. In any case,

350 the consequence for plant recruitment is that after nut dispersal by magpies, a large

351 fraction (at least 32.6\%) of the seeds remained on site until the following spring ready

352 to start the next regeneration stage.

353 As a final result, $4 \%$ of the cached nuts rendered an emerged seedling, thus

354 providing a net value of seed dispersal effectiveness up to the seedling stage that could

355 generate recruitment. In addition, the number of emerged seedlings might have been

356 higher if the final sampling had been conducted a few weeks later, as all the germinated

357 (but not emerged) seedlings showed a healthy radicle protruding in the soil. In fact,

358 since the arrival of magpies to the study area ca. 15 years ago, there is abundant walnut

359 seedling emergence around the farms at distances of dozens to hundreds of meters from

360 adult trees (authors' personal observation). Although this rarely translates into adult

361 walnut recruitment due to yearly ploughing, it is very likely that walnut expansion

362 would occur if ploughing were discontinued, as documented for example by Lenda et al.

363 (2012) for walnut dispersed by rooks in abandoned farms in Poland.

364 In summary, this study demonstrates the relevance of magpies as scatter-

365 hoarding dispersers of nut-producing trees, and for the first time provides an accurate

366 estimate of seed-dispersal effectiveness for a bird-plant interaction that is crucial for the

367 regeneration and expansion of temperate, large-seeded trees (Pesendorfer et al. 2016).

368 Magpies are abundant in open landscapes such as agricultural land and successional

369 shrublands, habitat types usually avoided by Eurasian jays for their nut-dispersal

370 activity (Gómez 2003; Pons and Pausas 2007; Leverkus et al. 2016), and where jays are 
371 often rare or absent (Andrén 1990; Pons and Pausas 2008; Cramp and Perris 1994). This

372 may increase the relevance of the magpie as a key species for the demography of nut-

373 producing trees in anthropogenic landscapes where habitat fragmentation and reduced

374 forest cover are common. In short, our results support the hypothesis that magpies act in

375 the regeneration and expansion of the Eurasian temperate forest, thus increasing the

376 number of corvid species with known key mutualistic roles for forest regeneration.

377

378 Acknowledgements

379 This study was supported by the projects CGL2014-53308-P of the Spanish

380 Government and Remedinal 3 (S2013/ MAE- 2719) of the Madrid Government

381 The Consejería de Medio Ambiente (Junta de Andalucía) provided fieldwork

382 permission. LMB was supported by a FPI scholarship (BES-2015-075276) from the

383 Spanish Government. AL acknowledges support by theUniversity of Granada and

384 Project GEISpain (CGL2014- 52838- C2- 1- R) funded by the Spanish Ministerio de

385 Economía y Competitividad, including European Union ERDF funds. We thank Dr.

386 E.W. Schupp and two anonymous reviewers for providing suggestions that enhanced

387 the manuscript.

388

389 References

390 Andrén H (1990) Despotic distribution, unequal reproductive success, and population

391 regulation in the jay Garrulus glandarius L. Ecology 71:1796-1803.

392 Baddeley A, Turner R (2005) Spatstat: An R package for analyzing spatial point

393 patterns. Journal of Statistical Software 12:1-42.

394 Birkhead TR (1991) The Magpies. The ecology and behaviour of Black-billed and

395 Yellow-billed Magpies. T \& AD Poyser, London. 
396 Bossema I (1979) Jays and oaks: an eco-ethological study of a symbiosis. Behaviour

$397 \quad 70: 1-116$.

398 Brodin A, Lundborg K (2003) Is hippocampal volume affected by specialization for

399 food hoarding in birds? Proceedings of the Royal Society of London B 270:1555-

$400 \quad 1563$.

401 Buxó R (1997) Arqueología de las plantas. Crítica, Barcelona.

402 Cain ML, Milligan BG, Strand AE (2000) Long-distance seed dispersal in plant

403 populations. American Journal of Botany 87:1217-1227.

404 Castro J, Hódar JA, Gómez JM (2006) Seed size. In: Basra A (ed) Handbook of seed

405 science and technology. Haworth's Food Products Press, New York, pp 397-427.

406 Castro J, Puerta-Piñero C, Leverkus AB, Moreno-Rueda G, Sánchez-Miranda A (2012)

407 Post-fire salvage logging alters a key plant-animal interaction for forest regeneration.

$408 \quad$ Ecosphere 3:art90.

409 Clarkson K, Eden SF, Sutherland WJ, Houston AI (1986) Density dependence and

410 magpie food hoarding. J Anim Ecol 55:111-121.

411 Cramp S, Perrins CM (Eds.) (1994) Handbook of the Birds of Europe the Middle East

412 and North Africa. The Birds of the Western Palearctic. Volume VIII. Crows to

413 Finches. Oxford University Press, Oxford.

414 Cristol W (2005) Walnut caching behavior of American Crows. Journal of Field

415 Ornithology 76:27-32.

416 Darley-Hill S, Johnson WC (1981). Acorn dispersal by the blue jay (Cyanocitta

$417 \quad$ cristata). Oecologia 50:231-232.

418 Feenders G, Smulders TV (2011) Magpies can use local cues to retrieve their food 419 caches. Animal Cognition 14:235-243.

420 Gómez JM (2003) Spatial patterns in long-distance dispersal of Quercus ilex acorns by 
421 jays in a heterogeneous landscape. Ecography 26:573-584.

422 Gómez JM (2004) Importance of microhabitat and acorn burial on Quercus ilex early 423 recruitment: non-additive effects on multiple demographic processes. Plant Ecology $424 \quad 172: 287-297$.

425 Grinnell J (1936) Up-hill planters. The Condor 38:80-82.

426 Healy SD, Krebs JR (1992) Food storing and the hippocampus in corvids: amount and 427 volume correlated. Proceedings of the Royal Society of London Series B, 248:241428245.

Henty CJ (1975) Feeding and food-hiding responses of Jackdaws and Magpies. Brit. $430 \quad$ Birds 68:463-466.

431 Homet-Gutiérrez P, Schupp EW, Gómez JM (2015) Naturalization of almond trees 432 (Prunus dulcis) in semi-arid regions of the Western Mediterranean. Journal of Arid 433 Environments 113:108-113.

434 Hougner C, Colding J, Söderqvist T (2006) Economic valuation of a seed dispersal 435 service in the Stockholm National Urban Park, Sweden. Ecological Economics $436 \quad 59: 364-374$.

437 Johnson WC, Webb III T (1989) The role of blue jays (Cyanocitta cristata L.) in the 438 post-glacial dispersal of fagaceous trees in eastern North America. Journal of 439 Biogeography 16:561-571.

440 Johnson WC, Adkisson CS, Crow TR, Dixon MD (1989) Nut caching by blue jays 441 (Cyanocitta cristata L.): implications for tree demography. American Midland $442 \quad$ Naturalist 138:357-370.

443 Källander H (2007) Food hoarding and use of stored food by Rooks Corvus frugilegus. $444 \quad$ Bird Study 54:192-198. 
445 Lenda M, SKórka P, Knops JMH, Morón D, Tworek S, Woyciechowski M (2012) Plant

446 establishment and invasions: an increase in a seed disperser combined with land

447 abandonment causes an invasion of the non-native walnut in Europe. Proceedings of

448 the Royal Society of London Series B, 279:1491-1497.

449 Leverkus AB, Rey-Benayas JM, Castro J (2016) Shifting demographic conflicts across

450 recruitment cohorts in a dynamic post-disturbance landscape. Ecology 97:2628-

4512639.

452 Martí R, Del Moral JC (Eds) (2003) Atlas de las aves reproductoras de España.

453 Dirección General de Conservación de la Naturaleza-Sociedad Española de

454 Ornitología. Madrid.

455 Martínez JG (2011) Urraca - Pica pica. In: Salvador A and Morales MB (eds.)

456 Enciclopedia virtual de los vertebrados españoles. Museo Nacional de Ciencias

457 Naturales, Madrid. http://www.vertebradosibericos.org (version 16-09-2011).

458 Morán-López T, Alonso CL, Díaz M (2015) Landscape effects on jay foraging behavior

459 decrease acorn dispersal services in dehesas. Acta Oecologica 69:52-64.

460 Mosandl R, Kleinert A (1998) Development of oaks (Quercus petraea (Matt.) Liebl.)

461 emerged from bird-dispersed seeds under old-growth pine (Pinus sylvestris L.)

462 stands. Forest Ecology and Management 106:35-44.

463 Pesendorfer MB, Sillett TS, Koeing WD, Morrison SA (2016) Scatter-hoarding corvids

464 as seed dispersers for oaks and pines: A review of a widely distributed mutualism

465 and its utility to habitat restoration. The Condor 118:215-237.

466 Pons J, Pausas JG (2007) Acorn dispersal estimated by radio-tracking. Oecologia

$467 \quad 153: 903-911$.

468 Pons J, Pausas JG (2008) Modelling jay (Garrulus glandarius) abundance and

469 distribution for oak regeneration assessment in Mediterranean landscapes. Forest 
471 Puerta-Piñero C, Brotons L, Coll L, González-Olabarría JR. (2012) Valuing acorn 472 dispersal and resprouting capacity ecological functions to ensure Mediterranean 473 forest resilience after fire. European Journal of Forest Research 131:835-844.

474 Richards TJ (1958) Concealment and recovery of food by birds, with some relevant 475 observations on squirrels. Brit. Birds 51:497-508.

476 R Core Team (2014) R: A language and environment for statistical computing. R 477 Foundation for Statistical Computing, Vienna, Austria. URL http://www.R$478 \quad$ project.org/.

479 Schupp EW, Fuentes M (1995) Spatial patterns of seed dispersal and the unification of 480 plant population ecology. Ecoscience 2:267-275.

481 Schupp EW, Jordano P, Gómez JM (2010) Seed dispersal effectiveness revisited: a $482 \quad$ conceptual review. New Phytologist 188:333-353.

483 Tamura N, Hayashi F (2008) Geographic variation in walnut seed size correlates with 484 hoarding behaviour of two rodent species. Ecological Research 23:607-614. 485 Thanos CA (1994) Aristotle and Theophrastus on plant-animal interactions; In M. 486 Arianoutsou \& R. Groves (Eds.), Plant-Animal Interactions in Mediterranean-Type 487 Ecosystems; (pp. 3-11). Netherlands: Kluwer Academic Press.

488 Vander Wall SB (1990) Food hoarding in animals. Chicago Press.

489 Vander Wall SB (2001) The evolutionary ecology of nut dispersal. The Botanical $490 \quad$ Review 67:74-117.

491 Waite RK (1985) Food caching and recovery by farmland corvids. Bird Study 32:45-49. 492 Zinkivskay A, Nazir F, Smulders TV (2009) What-where-when memory in magpies 493 (Pica pica). Animal Cognition 12:119-125. 


\begin{tabular}{|c|c|c|c|c|}
\hline & Date & Feeder & $\begin{array}{c}\text { \#Nuts } \\
\text { offered }\end{array}$ & $\begin{array}{c}\text { \#Nuts } \\
\text { dispersed }\end{array}$ \\
\hline \multirow{11}{*}{$\begin{array}{l}\text { Non radio-tagged } \\
\text { nuts }\end{array}$} & $05 / 09 / 15$ & 1 & 20 & 18 \\
\hline & 06/09/15 & 1 & 20 & 19 \\
\hline & 08/09/15 & 1 & 20 & 20 \\
\hline & 09/09/15 & 1 & 20 & 15 \\
\hline & $11 / 09 / 15$ & 1 & 20 & 14 \\
\hline & $13 / 09 / 15$ & 1 & 20 & 6 \\
\hline & $18 / 09 / 15$ & 1 & 20 & 15 \\
\hline & $21 / 10 / 15$ & 1 & 10 & 9 \\
\hline & $21 / 10 / 15$ & 2 & 10 & 4 \\
\hline & $26 / 10 / 15$ & 1 & 5 & 5 \\
\hline & & & $\Sigma=165$ & $\Sigma=125$ \\
\hline \multirow{23}{*}{$\begin{array}{l}\text { Radio-tagged } \\
\text { nuts }\end{array}$} & $25 / 10 / 15$ & 1 & 5 & 4 \\
\hline & & & 5 & 5 \\
\hline & $26 / 10 / 15$ & 1 & 5 & 1 \\
\hline & 27/10/15 & 1 & 5 & 4 \\
\hline & $28 / 10 / 15$ & 1 & 5 & 5 \\
\hline & 29/10/15 & 1 & 5 & 2 \\
\hline & & & 5 & 2 \\
\hline & $1 / 11 / 15$ & 1 & 5 & 4 \\
\hline & $2 / 11 / 15$ & 1 & 5 & 3 \\
\hline & $3 / 11 / 15$ & 1 & 5 & 4 \\
\hline & $5 / 11 / 15$ & 1 & 5 & 2 \\
\hline & $7 / 11 / 15$ & 2 & 5 & 3 \\
\hline & $9 / 11 / 15$ & 2 & 5 & 3 \\
\hline & $10 / 11 / 15$ & 2 & 3 & 1 \\
\hline & $10 / 11 / 15$ & 1 & 2 & 2 \\
\hline & $15 / 11 / 15$ & 1 & 3 & 1 \\
\hline & $17 / 11 / 15$ & 1 & 5 & 5 \\
\hline & $25 / 11 / 15$ & 1 & 5 & 3 \\
\hline & $01 / 12 / 15$ & 1 & 5 & 5 \\
\hline & $04 / 12 / 15$ & 1 & 5 & 2 \\
\hline & $10 / 12 / 15$ & 1 & 5 & 3 \\
\hline & $12 / 12 / 15$ & 1 & 4 & 4 \\
\hline & & & $\Sigma=102$ & $\Sigma=68$ \\
\hline
\end{tabular}

Table 1. Summary of the number of nuts offered and removed from feeders during the study period. 
491 Figure 1. Ortho-rectified aerial photograph of the study area, taken with a drone. The area surrounded by a dashed red line is the core site. The dashed yellow line delimitates

493 the "broadleaf" habitat, the green dashed line the "Pine" habitat, and the rest of the area

494 within the core site corresponds to the "Cropland" habitat. Yellow dots indicate the

495 position of cached nuts dispersed from feeder 1, and green dots that of cached nuts

496 dispersed from feeder 2. The orange triangles show the position of the feeders. One nut

497 with a radio-transmitter was dispersed towards the east outside the area of the picture

498 and is not shown here. The image was take with a GoPro 4 Black edition camera

499 attached to a drone (Phantom 2 UAV) during a photogrammetric flight at $50 \mathrm{~m}$ height

500 on $23^{\text {rd }}$ January 2016. The photos were processed with the Agisoft PhotoScan 1.2.0

501 software, which was also used for the final 10-cm pixel-resolution image.

502

503 Figure 2. Distribution of radio-tagged nuts dispersed by magpies. A) Histogram

504 showing the frequency of dispersal distances. B) Kernel-smoothed density of cached

505 nuts encountered in the core site for radio-labeled nuts dispersed from Feeder 1 (marked

506 as a red dot). The map shows the intensities of the point pattern generated by caching

507 points within the plot. Density of caching points reduces with increasing distances from

508 the feeder. The space occupied by gravel roads and buildings has been eliminated for

509 the analysis.

510

511 Figure 3. Path diagram indicating the stages in the qualitative component of seed-

512 dispersal effectiveness (SDE) for the magpie-walnut interaction. The numbers in the

513 boxes indicate the number of nuts available for the next demographic transition (green

514 boxes) and those that were lost for recruitment (red boxes). The yellow boxes indicate 
515 the starting (total number of monitored nuts) and the ending points (number of emerged

516 seedlings). Numbers in bracket show the transition probability for each stage from the

517 number of dispersed seeds. The height of the seedlings was 12.0 and $14.8 \mathrm{~cm}$,

518 respectively. Data of the three habitat types have been pooled for simplicity. Not-recov.

$519=$ Not recovered

520 


\section{Supplementary Material 1}

523 Figure S1. Characteristics of the feeders used in this study. The first feeder (Feeder 1 in

524 Figure 1 of the manuscript) consisted of an almost flat roof of a chicken house placed at

$5252.20 \mathrm{~m}$ above the ground plus a wooden slat that prevented the nuts from rolling down

526 (upper picture). The second feeder (Feeder 2 in Figure 1 of the manuscript) was a $30 \times$

$52740 \mathrm{~cm}$ wooden cage with a metal bottom, held $1.7 \mathrm{~m}$ from the ground by a metal post

528 and located below the canopy of a walnut tree (bottom picture). We knew from previous

529 observations that magpies foraged or perched regularly in both locations. The two

530 feeders were placed $100 \mathrm{~m}$ from each other.

531

532 Figure S2. Details of radio-transmitter insertion into a walnut. The nut was split open

533 with a knife, a portion of the kernel similar in weight to the transmitter was removed,

534 the transmitter was inserted into the nut with the antenna rolled, and finally the two

535 halves of the shell were glued together with superglue (Loctite $®$ ).

536

537 Supplementary Material 2. Video recording with a sensitive-movement camera in

538 Feeder 1 on 27 October 2015, showing three magpies at once, and two of them

539 retrieving a nut each (containing transmitters in this case). The time that appears in the

540 video is local time, one hour ahead of solar time (thus, it was 8 am solar time). It can be

541 observed that the second magpie that removed a nut flew westwards beyond a group of

542 trees, being lost at a distance of ca. $130 \mathrm{~m}$ from the feeder. This transmitter was not

543 found despite a thorough search at a distance up to $300 \mathrm{~m}$, and might represent an event

544 of long-distance dispersal. 
Effective nut dispersal by magpies (Pica pica L.) in a Mediterranean agroecosystem

Jorge Castro $^{1 *}$, Mercedes Molina-Morales ${ }^{2}$, Alexandro B. Leverkus ${ }^{1}$, Loreto MartínezBaroja $^{3}$, Lorenzo Pérez-Camacho ${ }^{3}$, Pedro Villar-Salvador ${ }^{3}$, Salvador Rebollo ${ }^{3}$ and José M. Rey-Benayas ${ }^{3}$

${ }^{1}$ Departamento de Ecología, Facultad de Ciencias, Universidad de Granada, E-18071 Granada, Spain.

${ }^{2}$ Departamento de Zoología, Facultad de Ciencias, Universidad de Granada, E-18071 Granada, Spain.

${ }^{3}$ Grupo de Investigación “Ecología y Restauración Forestal” FORECO. Departamento de Ciencias de la Vida, UD Ecología, Edificio de Ciencias, Universidad de Alcalá, 28805 Alcalá de Henares, Spain

*Author for Correspondence. Email: jorge@ugr.es

Author Contributions: JC, LPC, PVS, SR and JMRB conceived and designed the experiments. JC, MMM, AL and LMB performed the field work. JC, MMM and AL performed statistical analyses. JC wrote the first draft of the ms; all authors provided editorial advice. 
2 Scatter-hoarding animals such as corvids play a crucial role in the dispersal of nut-

3 producing tree species. This interaction is well known for some corvids, but remains

4 elusive for other species such as the magpie (Pica pica), an abundant corvid in

5 agroecosystems and open landscapes of the Palearctic region. In addition, the

6 establishment of the individual dispersed seeds, a prerequisite to determine seed-

7 dispersal effectiveness, never before has been documented for the interaction between

23 Key words: Corvidae, forest regeneration, Juglans, radio-tracking, scatter-hoarding, seed caching, seed dispersal effectiveness
Jorge Castro 11/12/2016 17:36

Eliminado: has Jorge Castro 28/11/2016 23:01

Eliminado: $\mathrm{W}$

Jorge Castro 28/11/2016 23:01

Eliminado: the effectiveness of Jorge Castro 22/11/2016 13:38

Eliminado: by

Jorge Castro 22/11/2016 13:39

Eliminado: proved

Jorge Castro 11/12/2016 17:10

Eliminado: seed magpies can be an effective scatter-hoarding disperser of a nut-producing tree species, suggesting that this bird species may play a key role for the regeneration and expansion 


\section{INTRODUCTION}

37 Seed dispersal of large-seeded species of paramount relevance in the context of

38 temperate forests is largely ascribed to a plant-animal interaction in which a vertebrate vector is responsible for direct seed transport (Vander Wall 1990; Johnson et al. 1997;

40 Pesendorfer et al. 2016). Several bird species from the Corvidae family are among the

41 most active dispersers for these trees, acting as scatter-hoarding animals that cache

42 seeds in a large number of locations across the landscape for later consumption,

43 disperse a very large number of seeds, and usually cover distances exceeding hundreds

44 or even thousands of meters (Bossema 1979; Darley-Hill and Johnson 1981; Lenda et

45 al. 2012; Pesendorfer et al. 2016). A fraction of the seeds may remain un-recovered,

46 providing the opportunity for seed germination and tree recruitment (Vander Wall 1990;

47 Pesendorfer et al. 2016). In fact, the interaction between corvids and many tree species from the Fagaceae or Juglandaceae plant families is considered a key mutualistic

49 relationship for the regeneration, colonization, and expansion of forests in the Northern

50 Hemisphere, helping to explain the post-glacial migration and current distribution of

51 temperate forests (Johnson and Webb III 1989; Johnson et al. 1997; Vander Wall 1990;

52 Mosandl and Kleinert 1998; Pesendorfer et al. 2016).

53 The role of corvids in the transport of nuts has been noted since ancient times (e.g. Aristotle and Theophrastus; Thanos 1994), and for decades has been intensively 55 studied in several species throughout the Holarctic region (e.g. Grinnell 1936; Richards 56 1958; Bossema 1979; Cristol 2005; Pesendorfer et al. 2016 [and references therein]). In

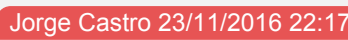

Eliminado: such as trees from the Fagaceae or Juglandaceae families,

Jorge Castro 22/11/2016 13:41

Eliminado: the

Jorge Castro 23/11/2016 22:20

Eliminado: effective

Jorge Castro 22/11/2016 13:42

Eliminado: huge amount

Jorge Castro 22/11/2016 13:42

Eliminado: be not recovered

Jorge Castro 23/11/2016 22:19

Eliminado: above-mentioned

Jorge Castro 23/11/2016 22:20

Con formato: Fuente: Cursiva

Jorge Castro 23/11/2016 22:20

Con formato: Fuente: Cursiva

Jorge Castro 22/11/2016 13:43

Eliminado: noticed

\section{Jorge Castro 22/11/2016 13:43}

Eliminado: - surely given the conspicuous interaction established between birds and tree species that were relevant for human welfare and nutrition- 
ascribed mostly to a single species, the European jay (Garrulus glandarius L.)

(Bossema 1979; Pesendorfer et al. 2016), and to a much lesser extent to the rook (Corvus frugilegus L.) (Waite 1985; Källender 2007; Lenda et al. 2012). Knowledge of the role of other corvids in the regeneration of these tree species in the Palearctic is almost negligible. In particular, the black-billed magpie (Pica pica L., hereafter referred to as "magpie"), a common corvid in Eurasia, is considered to have little relevance for

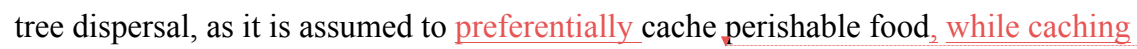
few nuts within short distances, and with a recovery time of only a few days (Henty 1975; Waite 1985; Birkhead 1991). Several pieces of evidence, however, suggest that magpies might be noteworthy vectors in nut dispersal. It is well established that magpies cache food items (Henty 1975; Clarkson et al. 1986; Birkhead 1991), have the capacity to recall cache locations (Zinkivskay et al. 2008; Feenders and Smulders 2011) and have a well-developed hippocampus (Healy and Krebs 1992; Brodin and Lundberg 2003), a brain region linked to spatial memory and food-storing behaviour. Magpies have also been suggested to be the most likely dispersers of almond trees in agroforestry systems (Homet-Gutiérrez et al. 2015), and reports on acorn dispersal, although very scant, are available (Birkhead 1991). In short, several clues support the idea that magpies might have an influential role in nut dispersal for Eurasian tree species. However, to date, the magnitude of nut dispersal and recovery rate for this bird have never been documented.

Although many studies have addressed the dispersal of nut-producing trees by corvids (e.g. review by Pesendorfer et al. 2016), a gap in knowledge persists concerning the implications of this mutualistic interaction for forest regeneration. Studies reporting a link between the vector and the plant are based mostly on evidence arising from synchronic observations of dispersal and seedling-recruitment patterns (e.g. Mosandl 
2012; Puerta-Piñero et al. 2012). This procedure has demonstrated beyond a doubt that the corvids are major vectors for nut dispersal. However, a fine-grained quantification of the effect of animal seed-dispersal vectors requires precise knowledge concerning the fate of the dispersed seed, an aspect seldom addressed in studies of seed dispersal (Schupp and Fuentes 1995; Schupp et al. 2010) and, as far as we know, never addressed for the interaction between corvids and nut-producing tree species. The use of radio-

110 tracking with small transmitters embedded in the seed is a recent method to study nut

111 dispersal (e.g. Pons and Pausas 2007; Tamura and Hayashi 2008; Morán-López et al. 2015). By replacing the transmitter-containing nut after dispersal by another nonmanipulated nut able to germinate and continue with the recruitment processes, we might be able to monitor the magnitude of effective seed dispersal. Although this method could still underestimate the probability of recruitment in case the dispersed nuts are re-cached, it has the potential to provide a more accurate measure of the

117 tree species. qualitative component of seed-dispersal effectiveness (sensu Schupp et al. 2010) and a more comprehensive picture of the role of corvids in the recruitment of nut-producing

In this study, we analyse the activity of magpies, a common corvid in open landscapes and agroforestry systems throughout Eurasia, in the dispersal of the common walnut (Juglans regia L.). Nut removal, dispersal distance, cache location, and seedling emergence were precisely monitored, providing the necessary framework to analyse the seed-dispersal effectiveness mediated by a vertebrate vector. Given the already known scatter-hoarding behaviour of magpies and their capacity to remember caching sites, together with observations made under field conditions supporting magpie nut dispersal (Birkhead 1991; Omat et al. 2015, author's personal observations), we hypothesise that 

terms of habitat selection, caching type, and dispersal distance? 3) What is the recovery rate of cached nuts? And 4) what are the germination and emergence rates of unrecovered nuts? The response to these questions will allow us to determine an accurate value of the qualitative component of seed-dispersal effectiveness and the role of magpies as dispersers for a nut-producing tree.

The study was conducted in an agroforestry system located in the "Vega de Granada" (SE Spain, $37^{\circ} 10^{\prime} 03.43^{\prime \prime} \mathrm{N}, 3^{\circ} 36^{\prime} 57.80^{\prime \prime} \mathrm{W}$ ), a flat and irrigated agricultural area of small-sized farms located at ca. $650 \mathrm{~m}$ a.s.l. The area is used mainly for crop production, mostly vegetables, maize, tree plantations, and pasture. The soil is deep and loamy, and the climate is Mediterranean-type, with hot, dry summers and mild winters. IFAPA Research Field Station, $1.5 \mathrm{~km}$ from the study site). Common walnut (Juglans regia; target plant species of this study) is traditionally grown in the farms of the area (presumably since Roman times; Buxó 1997), usually as scattered trees close to houses. The study site was a 1.8-ha farm (hereafter referred to as "core site") plus surrounding fields where nut dispersal could be registered with radio-tracking. The core site, which is used mostly for research purposes, is divided into three main areas (habitats, hereafter), namely 1) a broadleaf stand, 2) a pine stand, and 3) cropland (Fig. 
euroamericana (Dode) Guinier, clone I-214) and hybrid walnut (Juglans major $\mathrm{x}$

Juglans regia MJ 209xRa) with an even number of individuals, all trees being evenly spaced at a planting density of 400 individuals $\mathrm{ha}^{-1}$. Tree diameter at breast height in October 2015 was $27.6 \pm 0.3 \mathrm{~cm}$ for poplar and $9.6 \pm 0.2 \mathrm{~cm}$ for hybrid walnut. The pine habitat consisted of $2000 \mathrm{~m}^{2}$ of Aleppo pine saplings (Pinus halepensis Mill.), evenly spaced at a density of 1200 individuals $\mathrm{ha}^{-1}$. Saplings had a height of $1.95 \pm 0.04 \mathrm{~m}$ by October 2015, with lower branches touching the ground. The cropland habitat covers the rest of the core site area and is used for vegetable production (Fig. 1). It also contains some scattered fruit trees (3-6 m tall) such as plums, apples, pears, persimmons, fig trees and peaches, for a total of 34 individuals. The three habitat types were ploughed in late August 2015, one week before the start of this study. The black-billed magpie is a corvid widely distributed across the Palearctic and is the most abundant corvid in southern Europe (Cramp and Perrins 1994; Martí and Del Moral 2003). It is particularly abundant in agroecosystems and open landscapes where other nut-dispersing corvids such as the Europen jay are usually absent (Martí and Del Moral 2003; Martínez 2011). The magpie is a common species in the Iberian Peninsula, but was absent in the study area until some years ago despite being common in nearby areas at distances of ca. $20 \mathrm{~km}$, Regular bird sampling in the study area since 1985 (J.C.; unpublished data) showed that they appeared in low numbers (occasional individuals) in 2002 and started nesting in 2008. Their population has steadily increased since then, currently being a common breeding bird in the area. Coinciding with its arrival to the study site, the emergence of walnut seedlings in the fields became evident. In 2012 we made preliminary observations and confirmed that magpies were dispersing nuts picked directly from J. regia trees of the area. These observations were not 

this study.

189

methodical, but they led us to formulate the hypotheses and sampling design to conduct

\section{Sampling of the magpie-walnut interaction}

We studied the interaction between magpie and walnut by using three complementary approaches: 1) monitoring the removal of non radio-tagged nuts offered in feeders, 2) monitoring the removal and dispersal distance of radio-tagged nuts offered in feeders, and 3) monitoring post-dispersal recovery rate and seedling recruitment for nuts that replaced the radio-tagged nuts. Nut dispersal was sampled in all cases within the period of natural nut ripening and dispersal in the study area. The coordinates of all dispersed nuts and feeders were marked with a GPS, which allowed dispersal distances to be calculated using Quantum GIS. For the core site, we also constructed an ortho-photo from 5-cm/pixel-resolution photos (Fig. 1).

The removal of non radio-tagged nuts placed in feeders was monitored from September 5 to October 26, 2015 (see Fig. S1 for feeder details). A total of 165 nuts were offered in bunches of 20 (occasionally 10 or 5; Table 1), and a video camera with a continuous recording system and day and night vision was placed at ca. $1.5 \mathrm{~m}$ from the nuts (Miniature Motion Activated DVR Resolution SSC-758HQ, coupled with Led Color Cameras SSC-56C36; Advance Security, Belleville, Illinois, USA). Also, we conducted non-systematic direct observations from a hide, A fraction of the nuts (120) were weighed before placing them in the feeders, and they were identified with a number on the shell using waterproof, permanent ink. Overall, this procedure was chosen as an initial method to test nut removal by magpies (i.e. before using radio transmitters) to reduce nut manipulation and potential distrust by magpies. It also allowed us to ascertain the disperser's identity and activity. 
Biotrack, Wareham, Dorset, UK; weight: $2.2 \mathrm{~g}$; mean life span: 3 months) was placed inside the nut, which allowed us to relocate dispersed nuts and to measure exact dispersal distances. Nut removal was also video-recorded with a movement-sensitive system (Moultrie M-990i; Moultrie Products, Alabama, USA) as well as with day and night vision. For each sample, the walnut shell was split open along the suture, a portion of the kernel of similar weight to the transmitter was excised, the transmitter with its antenna rolled up was placed inside the nut, and then the two halves of the nut were glued together with Loctite ${ }^{\circledR}$ (Supplementary Material 1, Fig. S2). Five transmittercontaining nuts were used, either in a single feeder or divided into groups of 2 and 3 nuts in the two feeders simultaneously. Eventually, we noted that magpies refused to

233 pick some radio-tagged nuts from the feeders, which might have been due to desiccation or to any other cue that we could not identify. In those cases we changed the transmitter to another nut. Once removed from the feeders, the nuts with the radio-transmitter were located (usually within a few hours after dispersal) with the help of a radio-tracking receiver with a unidirectional Yagi antenna (Biotrack, Wareham, Dorset, UK) plus a hand-held metal detector (White's Auto-Scan Personal Search Detector, Tulsa,

239 Oklahoma, USA) for exact location of the nut/transmitter, which is particularly necessary for buried nuts. The caching characteristics were categorized as: 1) Superficial, nuts left visible, on the soil surface; 2) Buried, nuts buried in bare soil; and

242 3) Under plant material, nuts hidden below leaf litter or below leaves of live vegetation, the latter including forbs, grasses, vegetables or the pine branches that were touching the ground in the pine habitat. 
with a transmitter was located, the nut was placed back in the feeders, and a nonmanipulated nut of similar weight was placed in the same location. The point where the

249 nut was found was marked with a wooden stake (12 cm x $9 \mathrm{~mm}$ x $9 \mathrm{~mm}) 50 \mathrm{~cm}$ away from the nut, and a small metal rod was placed under the nut to facilitate later relocation

251

with the metal detector. Approximately 6 months later (from 5 to 24 May 2016), coinciding with the period of seedling emergence in the study area, we sampled the status of all those nuts, considering as categories: absent (assigned as recovered), nongerminated, germinated, and emerged seedling. In the case of emerged seedlings we also noted seedling height.

\section{Data analyses}

We analysed differences in the weight among removed and non-removed nuts from the feeders with a one-way ANOVA. The effect of nut weight on dispersal distance was assessed with a linear mixed model in the lme R package (Pinheiro et al. 2016), using nut as a random effect because the same transmitter-containing nuts were placed in the feeders several times. Differences in caching types were analysed with contingency tests, and the effect of caching type on recovery rates with a glm with a binomial distribution. The effect of habitat type and distance from the feeder on nut dispersal was analysed with spatial statistics. This analysis was restricted to the core site given that in this area the habitats persisted through the study period, whereas outside the core site the crops changed from September to December, precluding definition of permanent habitats. For this, we fitted point process models with the spatstat R package (Baddeley \& Turner 2005). The models considered a non-homogeneous Poisson process, with the density of dispersed nuts within the core site depending on two spatial covariates: 
habitat type (broadleaf, pine or farmland) and a map of the distance of each $1 \times 1 \mathrm{~m}$ pixel to the feeder. The performance of this model was assessed through likelihood ratio tests during model simplification. This procedure was performed for the nuts dispersed

275 from Feeder 1, as the number of nuts from Feeder 2 was insufficient to perform this analysis. Analyses were performed with R version 3.1.1 in all cases (R Core Team 2014).

\section{1. Nut removal from feeders}

281 A total of 193 nuts were removed from feeders, including nuts with and without transmitters (68 and 125, respectively; Table 1). In $98 \%$ of the cases, the disperser was video-recorded or directly observed from the hide, and it was a magpie in all cases. Magpies in no case consumed nuts in the feeders, and the number of nuts removed was one in all dispersal events. The number of magpies observed simultaneously in the feeders ranged from 1 to 5 . Removed nuts were heavier $(9.44 \pm 0.17 \mathrm{~g})$ than nonremoved nuts $(8.67 \pm 0.32 \mathrm{~g} ; \mathrm{F}=4.47$, d.f. $=1,118, \mathrm{p}=0.037)$. Overall, magpies showed a high activity, and were able to remove all or most of the nuts within a few hours (Table 289 1)

\section{Dispersal distance and caching characteristics}

292 Dispersal distance was measured for 66 radio-tagged nuts. Mean dispersal distance was $29339.6 \pm 4.5 \mathrm{~m}$, with a range of 4.1 to $158.5 \mathrm{~m}$ (Fig. 2a). Two nuts containing transmitters 294 were not found despite thorough searching up to a distance of at least $300 \mathrm{~m}$ from the 295 core site (not considered for analyses), and they were likely carried long-distances based 

and $33.3 \%$ in the pine habitat, although there were no significant differences among

on video-camera recordings of these nuts (see Supplementary Material 2 for a video of one of the cases). Nut weight did not affect dispersal distance (L.Ratio $=0.58, p=0.45$ ).

Of the dispersed nuts, $10.6 \%$ were not cached but rather consumed immediately after removal from the feeder (the nut was found open with the transmitter partially or entirely outside), whereas the remaining $89.4 \%$ (59 nuts) were cached. Of those, $55.9 \%$ were buried in the soil (at 1-3 cm depth in all cases), $42.4 \%$ cached under plant material, and only one $(1.7 \%)$ was left on the ground surface $($ Chisq $=25.36, d f=2, p<0.001)$. In all cases the nuts were cached individually. Two of the nuts cached under plant material were located on a roof, although still hidden below litter.

The point process models did not show a significant effect of habitat type on the density of dispersed nuts $(\Delta \mathrm{Dev}=0.94, \mathrm{df}=2, \mathrm{p}=0.63)$, but they showed a significant negative effect of distance from the feeder $(\Delta \mathrm{Dev}=114.62, \mathrm{df}=1, \mathrm{p}<0.001 ;$ Fig. $2 \mathrm{~b})$.

\section{Nut recovery and seedling recruitment}

By May 2016 we were able to determine the fate of 49 of the 59 cached radio-tracked nuts; the remaining 10 nuts were either lost (four sampling points within the core site could not be relocated) or dispersed outside the core site, where the ground was tilled before the time of sampling (thus provoking the loss of the sampling point). Of these 49 nuts, $67.3 \%$ were recovered, $20.4 \%$ did not germinate, $12.2 \%$ germinated (including emerged ones), and $4.1 \%$ produced an emerged seedling (Fig. 3).

Nut recovery was $73.5 \%$ in the cropland habitat, $57.1 \%$ in the broadleaf habitat, habitat types $(\mathrm{ChiSq}=3.79$, d.f. $=2, \mathrm{p}=0.15)$. Nut recovery tended to decrease with jncreasing distance to the feeder, with non-recovered nuts being at an average distance
Eliminado: dispersal according to records by the

Jorge Castro 22/11/2016 13:54

Eliminado: $\mathrm{s}$

Jorge Castro 22/11/2016 13:54

Eliminado: for

Jorge Castro 22/11/2016 13:55

Eliminado: of the nuts

Jorge Castro 22/11/2016 13:55

Eliminado: the

Jorge Castro 22/11/2016 13:56

Eliminado: out

Jorge Castro 22/11/2016 13:57

Eliminado: with radio-tracking that were cached

\section{Jorge Castro 22/11/2016 13:57}

Eliminado: moment 
336 trend was not significant (logistic regression, $\mathrm{ChiSq}=1.61$, d.f. $=1, \mathrm{p}=0.20$ ).

We could not unequivocally determine the animal that removed the cached nuts,

338 but we often observed magpies recovering nuts in the study area, and found a large number of nuts consumed and opened in two valves as is characteristic in magpies

340 (Homet-Guitérrez et al. 2015; author's personal observation). No other animal was

341 directly observed removing the nuts dispersed by the magpies. Recovery activity spanned the entire study period, and we observed magpies consuming recovered nuts until early May 2016.

\section{DISCUSSION}

346 In this study, the magpie, an abundant corvid in Eurasian agroecosystems and open

347 landscapes, proved to be an effective disperser of a large-seeded species, moving a large number of walnuts over dispersal distances that reached $158 \mathrm{~m}$. Furthermore, a fraction of the nuts was not recovered after caching and resulted in effective early seedling

350 recruitment. Magpies had previously been suggested as dispersers for nut-producing tree species such as oaks (Birkhead 1991) or almond trees (Homet-Gutiérrez et al. 2015), but this interaction had never been demonstrated or measured in the context of

353 plant recruitment. Our study contributes to the understanding of the role of scatterhoarding corvids in the regeneration of Eurasian forests, and provides for the first time precise information of the qualitative component of seed-dispersal effectiveness for the 356 interaction between birds and nut-producing trees. 
Most of the nuts that were offered in the feeders were quickly dispersed and cached, and

368 wandered for a few seconds as if selecting the most preferable site, presumably checking for potential competitors that could steal the cached nut. In fact, in some cases

only a small fraction (ca. 10\%) was consumed just after removal. This behaviour is typical in scatter-hoarding animals, which display vigorous dispersal activity when the resource is abundant presumably in order to accumulate as much of it as possible during the short period of availability (Clarkson et al. 1986; Vander Wall 2001). After nut removal from feeders or trees, magpies also displayed a behaviour similar to that of other corvids (Bossema 1979; Cristol 2005). On arriving to a place to hide the nut, they they flew away with the nut and searched for another site. To cache the nut, they pushed it with the beak, sometimes hammering on it to bury it in the soil, and then they covered the site with soil or litter in such a way that the exact caching point became undetectable to the human eye (see Birkhead 1991 for a description of similar behaviour). In addition, the majority of the cached nuts were buried in the soil or hidden under plant material, both being microhabitats that may favour seed germination and seedling recruitment by reducing the risk of predation and desiccation (Bossema 1979; Vander Wall 1990, 2001; Gómez 2004). Furthermore, magpies preferred heavier nuts, therefore favouring a trait (large seed mass) that may enhances seedling establishment (Castro et al. 2006).

The observed dispersal distances lie within the lower range described for the rook, a corvid with a documented role in walnut dispersal (Lenda et al. 2012). Nonetheless, the body mass of the rook (around $500 \mathrm{~g}$ ) is much larger than the mass of the magpie (around $200 \mathrm{~g}$ ). In addition, two of the transmitters were lost, perhaps as a consequence of long-distance dispersal. In fact, we observed several events in which a magpie flying from a feeder with a nut was lost in the distance, likely far beyond the 
maximum dispersal distance recorded (Supplementary Material 2). In any case, $7.3 \%$ of

the nuts were dispersed beyond $100 \mathrm{~m}$, a distance and proportion great enough to support the contention that magpies can act as long-distance seed dispersers (Cain et al. 2000). Thus, magpies can play a relevant role in the expansion of nut-producing trees into new areas, a key step for the regeneration of the temperate forest (Pesendorfer et al.

The seed rain generated also supports the idea that magpies are effective dispersers in agroecosystems and agroforestry mosaics, since nuts were invariably cached alone, one by one, and were widely distributed throughout different habitats of the landscape. Some consequences of the spatial structuring of the seed rain for plant recruitment also seems plausible, as shown by the facts that caching density decreased

with distance from the source (as it is ultimately expected in a cost-benefit trade-off;

\section{Clarkson et al. 1986), or that there were significant differences in caching}

characteristics. Nonetheless, our results are based in a single study site, which precludes generalization of patterns. Further studies including more study areas and larger sample size would be necessary to ascertain the relationship between habitat characteristics, dispersal distance, and its potential implication for effective long-distance dispersal.

413 Radio-tracking, combined with the monitoring of the fate of seeds that replace the

414 dispersed, radio-tagged seed, has proved to be an appropriate method to answer these 415 questions.

\section{Post-dispersal nut recovery and seed dispersal effectiveness}

Radio-tracking also allowed us to obtain accurate estimates of nut recovery, which

419 reached $67 \%$ ca. 8 months after dispersal. Magpies were the only animals observed

\section{Jorge Castro 27/11/2016 23:07}

Eliminado: despite a reduction in caching density with distance from the source (as it is ultimately expected in a cost-benefit trade-off; Clarkson et al. 1986).

Eliminado: nuts cached at larger distances from the feeder tended to have a lower

recovery rate, which might be due to a lower pilfering rate with increasing distance (Clarkson et al 1986) or a reduction in memorization capacity and recovering success

due to an exponential increase in foraging

area. In any case, this trend was not significant, due possibly to low sample size. Jorge Castro 27/11/2016 22:55

Eliminado: are

Jorge Castro 27/11/2016 22:55

Eliminado: needed 
animals appear to play a minor role in this system, as throughout the study period we found only three nuts with marks of chewing by rodents on the shell vs. a high number (not recorded) of nuts opened in two halves as magpies do. We cannot discount pilfering by other magpies, either, or the re-caching by the original magpie. In any case, the consequence for plant recruitment is that after nut dispersal by magpies, a large fraction (at least $32.6 \%$ ) of the seeds remained on site until the following spring ready to start the next regeneration stage. As a final result, $4 \%$ of the cached nuts rendered an emerged seedling, thus providing a net value of seed dispersal effectiveness up to the seedling stage that could generate recruitment. In addition, the number of emerged seedlings might have been higher if the final sampling had been conducted a few weeks later, as all the germinated (but not emerged) seedlings showed a healthy radicle protruding in the soil. In fact, since the arrival of magpies to the study area ca. 15 years ago, there is abundant walnut seedling emergence around the farms at distances of dozens to hundreds of meters from adult trees (authors' personal observation). Although this rarely translates into adult walnut recruitment due to yearly ploughing, it is very likely that walnut expansion would occur if ploughing were discontinued, as documented for example by Lenda et al. (2012) for walnut dispersed by rooks in abandoned farms in Poland.

In summary, this study demonstrates the relevance of magpies as scatterhoarding dispersers of nut-producing trees, and for the first time provides an accurate estimate of seed-dispersal effectiveness for a bird-plant interaction that is crucial for the regeneration and expansion of temperate, large-seeded trees (Pesendorfer et al. 2016).

Magpies are abundant in open landscapes such as agricultural land and successional shrublands, habitat types usually avoided by Eurasian jays for their nut-dispersal activity (Gómez 2003; Pons and Pausas 2007; Leverkus et al. 2016), and where jays are 

may increase the relevance of the magpie as a key species for the demography of nut-

often rare or absent (Andrén 1990; Pons and Pausas 2008; Cramp and Perris 1994). This producing trees in anthropogenic landscapes where habitat fragmentation and reduced forest cover are common. In short, our results support the hypothesis that magpies act in the regeneration and expansion of the Eurasian temperate forest, thus increasing the number of corvid species with known key mutualistic roles for forest regeneration.

\section{Acknowledgements}

This study was supported by the projects CGL2014-53308-P of the Spanish Government and Remedinal 3 (S2013/ MAE- 2719) of the Madrid Government The Consejería de Medio Ambiente (Junta de Andalucía) provided fieldwork permission. LMB was supported by a FPI scholarship (BES-2015-075276) from the Spanish Government. AL acknowledges support by theUniversity of Granada and Project GEISpain (CGL2014-52838-C2-1-R) funded by the Spanish Ministerio de Economía y Competitividad, including European Union ERDF funds. We thank Dr. $\underline{\text { E.W. Schupp and two anonymous reviewers for providing suggestions that enhanced }}$ the manuscript.

\section{References}

Andrén H (1990) Despotic distribution, unequal reproductive success, and population regulation in the jay Garrulus glandarius L. Ecology 71:1796-1803.

Baddeley A, Turner R (2005) Spatstat: An R package for analyzing spatial point patterns. Journal of Statistical Software 12:1-42.

Birkhead TR (1991) The Magpies. The ecology and behaviour of Black-billed and Yellow-billed Magpies. T \& AD Poyser, London. 
Bossema I (1979) Jays and oaks: an eco-ethological study of a symbiosis. Behaviour 70:1-116.

Brodin A, Lundborg K (2003) Is hippocampal volume affected by specialization for food hoarding in birds? Proceedings of the Royal Society of London B 270:15551563.

Buxó R (1997) Arqueología de las plantas. Crítica, Barcelona.

Cain ML, Milligan BG, Strand AE (2000) Long-distance seed dispersal in plant populations. American Journal of Botany 87:1217-1227.

Castro J, Hódar JA, Gómez JM (2006) Seed size. In: Basra A (ed) Handbook of seed science and technology. Haworth's Food Products Press, New York, pp 397-427.

Castro J, Puerta-Piñero C, Leverkus AB, Moreno-Rueda G, Sánchez-Miranda A (2012) Post-fire salvage logging alters a key plant-animal interaction for forest regeneration. Ecosphere 3:art90.

Clarkson K, Eden SF, Sutherland WJ, Houston AI (1986) Density dependence and magpie food hoarding. J Anim Ecol 55:111-121.

Cramp S, Perrins CM (Eds.) (1994) Handbook of the Birds of Europe the Middle East and North Africa. The Birds of the Western Palearctic. Volume VIII. Crows to Finches. Oxford University Press, Oxford.

Cristol W (2005) Walnut caching behavior of American Crows. Journal of Field Ornithology 76:27-32.

Darley-Hill S, Johnson WC (1981). Acorn dispersal by the blue jay (Cyanocitta cristata). Oecologia 50:231-232.

Feenders G, Smulders TV (2011) Magpies can use local cues to retrieve their food caches. Animal Cognition 14:235-243.

Gómez JM (2003) Spatial patterns in long-distance dispersal of Quercus ilex acorns by 
Gómez JM (2004) Importance of microhabitat and acorn burial on Quercus ilex early recruitment: non-additive effects on multiple demographic processes. Plant Ecology

$519 \quad 172: 287-297$.

520 Grinnell J (1936) Up-hill planters. The Condor 38:80-82.

Healy SD, Krebs JR (1992) Food storing and the hippocampus in corvids: amount and volume correlated. Proceedings of the Royal Society of London Series B, 248:241245.

Henty CJ (1975) Feeding and food-hiding responses of Jackdaws and Magpies. Brit. Birds 68:463-466.

Homet-Gutiérrez P, Schupp EW, Gómez JM (2015) Naturalization of almond trees (Prunus dulcis) in semi-arid regions of the Western Mediterranean. Journal of Arid Environments 113:108-113.

Hougner C, Colding J, Söderqvist T (2006) Economic valuation of a seed dispersal service in the Stockholm National Urban Park, Sweden. Ecological Economics $59: 364-374$.

Johnson WC, Webb III T (1989) The role of blue jays (Cyanocitta cristata L.) in the

Johnson WC, Adkisson CS, Crow TR, Dixon MD (1989) Nut caching by blue jays (Cyanocitta cristata L.): implications for tree demography. American Midland

$537 \quad$ Naturalist 138:357-370.

Källander H (2007) Food hoarding and use of stored food by Rooks Corvus frugilegus.

Bird Study 54:192-198. 

establishment and invasions: an increase in a seed disperser combined with land abandonment causes an invasion of the non-native walnut in Europe. Proceedings of the Royal Society of London Series B, 279:1491-1497.

Leverkus AB, Rey-Benayas JM, Castro J (2016) Shifting demographic conflicts across recruitment cohorts in a dynamic post-disturbance landscape. Ecology 97:26282639

547 Martí R, Del Moral JC (Eds) (2003) Atlas de las aves reproductoras de España. Dirección General de Conservación de la Naturaleza-Sociedad Española de Ornitología. Madrid.

Martínez JG (2011) Urraca-Pica pica. In: Salvador A and Morales MB (eds.) Enciclopedia virtual de los vertebrados españoles. Museo Nacional de Ciencias Naturales, Madrid. http://www.vertebradosibericos.org (version 16-09-2011). decrease acorn dispersal services in dehesas. Acta Oecologica 69:52-64. emerged from bird-dispersed seeds under old-growth pine (Pinus sylvestris L.) stands. Forest Ecology and Management 106:35-44. as seed dispersers for oaks and pines: A review of a widely distributed mutualism and its utility to habitat restoration. The Condor 118:215-237.

Pons J, Pausas JG (2007) Acorn dispersal estimated by radio-tracking. Oecologia 153:903-911.

Pons J, Pausas JG (2008) Modelling jay (Garrulus glandarius) abundance and 564 distribution for oak regeneration assessment in Mediterranean landscapes. Forest 

dispersal and resprouting capacity ecological functions to ensure Mediterranean forest resilience after fire. European Journal of Forest Research 131:835-844.

Richards TJ (1958) Concealment and recovery of food by birds, with some relevant observations on squirrels. Brit. Birds 51:497-508.

572 R Core Team (2014) R: A language and environment for statistical computing. R Foundation for Statistical Computing, Vienna, Austria. URL http://www.Rproject.org/.

Schupp EW, Fuentes M (1995) Spatial patterns of seed dispersal and the unification of plant population ecology. Ecoscience 2:267-275.

Schupp EW, Jordano P, Gómez JM (2010) Seed dispersal effectiveness revisited: a conceptual review. New Phytologist 188:333-353.

Tamura N, Hayashi F (2008) Geographic variation in walnut seed size correlates with hoarding behaviour of two rodent species. Ecological Research 23:607-614.

Thanos CA (1994) Aristotle and Theophrastus on plant-animal interactions; In M. Arianoutsou \& R. Groves (Eds.), Plant-Animal Interactions in Mediterranean-Type Ecosystems; (pp. 3-11). Netherlands: Kluwer Academic Press.

584 Vander Wall SB (1990) Food hoarding in animals. Chicago Press.

Vander Wall SB (2001) The evolutionary ecology of nut dispersal. The Botanical Review 67:74-117.

587 Waite RK (1985) Food caching and recovery by farmland corvids. Bird Study 32:45-49.

Zinkivskay A, Nazir F, Smulders TV (2009) What-where-when memory in magpies 


\begin{tabular}{|c|c|c|c|c|}
\hline & Date & Feeder & $\begin{array}{l}\text { \#Nuts } \\
\text { offered }\end{array}$ & $\begin{array}{c}\text { \#Nuts } \\
\text { dispersed }\end{array}$ \\
\hline \multirow{11}{*}{$\begin{array}{l}\text { Non radio-tagged } \\
\text { nuts }\end{array}$} & $05 / 09 / 15$ & 1 & 20 & 18 \\
\hline & $06 / 09 / 15$ & 1 & 20 & 19 \\
\hline & $08 / 09 / 15$ & 1 & 20 & 20 \\
\hline & $09 / 09 / 15$ & 1 & 20 & 15 \\
\hline & $11 / 09 / 15$ & 1 & 20 & 14 \\
\hline & $13 / 09 / 15$ & 1 & 20 & 6 \\
\hline & $18 / 09 / 15$ & 1 & 20 & 15 \\
\hline & $21 / 10 / 15$ & 1 & 10 & 9 \\
\hline & $21 / 10 / 15$ & 2 & 10 & 4 \\
\hline & $26 / 10 / 15$ & 1 & 5 & 5 \\
\hline & & & $\Sigma=165$ & $\Sigma=125$ \\
\hline \multirow{23}{*}{$\begin{array}{l}\text { Radio-tagged } \\
\text { nuts }\end{array}$} & $25 / 10 / 15$ & 1 & 5 & 4 \\
\hline & & & 5 & 5 \\
\hline & $26 / 10 / 15$ & 1 & 5 & 1 \\
\hline & $27 / 10 / 15$ & 1 & 5 & 4 \\
\hline & $28 / 10 / 15$ & 1 & 5 & 5 \\
\hline & 29/10/15 & 1 & 5 & 2 \\
\hline & & & 5 & 2 \\
\hline & $1 / 11 / 15$ & 1 & 5 & 4 \\
\hline & $2 / 11 / 15$ & 1 & 5 & 3 \\
\hline & $3 / 11 / 15$ & 1 & 5 & 4 \\
\hline & $5 / 11 / 15$ & 1 & 5 & 2 \\
\hline & $7 / 11 / 15$ & 2 & 5 & 3 \\
\hline & $9 / 11 / 15$ & 2 & 5 & 3 \\
\hline & $10 / 11 / 15$ & 2 & 3 & 1 \\
\hline & $10 / 11 / 15$ & 1 & 2 & 2 \\
\hline & $15 / 11 / 15$ & 1 & 3 & 1 \\
\hline & $17 / 11 / 15$ & 1 & 5 & 5 \\
\hline & $25 / 11 / 15$ & 1 & 5 & 3 \\
\hline & $01 / 12 / 15$ & 1 & 5 & 5 \\
\hline & $04 / 12 / 15$ & 1 & 5 & 2 \\
\hline & $10 / 12 / 15$ & 1 & 5 & 3 \\
\hline & $12 / 12 / 15$ & 1 & 4 & 4 \\
\hline & & & $\Sigma=102$ & $\Sigma=68$ \\
\hline
\end{tabular}

Table 1. Summary of the number of nuts offered and removed from feeders during the study period. 


\section{Figure captions}

491

Figure 1. Ortho-rectified aerial photograph of the study area, taken with a drone. The area surrounded by a dashed red line is the core site. The dashed yellow line delimitates the "broadleaf" habitat, the green dashed line the "Pine" habitat, and the rest of the area within the core site corresponds to the "Cropland" habitat. Yellow dots indicate the position of cached nuts dispersed from feeder 1, and green dots that of cached nuts dispersed from feeder 2. The orange triangles show the position of the feeders. One nut with a radio-transmitter was dispersed towards the east outside the area of the picture and is not shown here. The image was take with a GoPro 4 Black edition camera attached to a drone (Phantom 2 UAV) during a photogrammetric flight at $50 \mathrm{~m}$ height on $23^{\text {rd }}$ January 2016. The photos were processed with the Agisoft PhotoScan 1.2.0 software, which was also used for the final 10-cm pixel-resolution image.

Figure 2. Distribution of radio-tagged nuts dispersed by magpies. A) Histogram showing the frequency of dispersal distances. B) Kernel-smoothed density of cached nuts encountered in the core site for radio-labeled nuts dispersed from Feeder 1 (marked as a red dot). The map shows the intensities of the point pattern generated by caching points within the plot. Density of caching points reduces with increasing distances from the feeder. The space occupied by gravel roads and buildings has been eliminated for the analysis.

Figure 3. Path diagram indicating the stages in the qualitative component of seeddispersal effectiveness (SDE) for the magpie-walnut interaction. The numbers in the boxes indicate the number of nuts available for the next demographic transition (green 
517 the starting (total number of monitored nuts) and the ending points (number of emerged

518 seedlings), Numbers in bracket show the transition probability for each stage from the number of dispersed seeds. The height of the seedlings was 12.0 and $14.8 \mathrm{~cm}$,

520 respectively. Data of the three habitat types have been pooled for simplicity. Not-recov.

521 $=$ Not recovered.

522 
526

527

528

529

530

531

\section{Supplementary Material 1}

Figure S1. Characteristics of the feeders used in this study. The first feeder (Feeder 1 in Figure 1 of the manuscript) consisted of an almost flat roof of a chicken house placed at $2.20 \mathrm{~m}$ above the ground plus a wooden slat that prevented the nuts from rolling down (upper picture). The second feeder (Feeder 2 in Figure 1 of the manuscript) was a $30 \times$ $40 \mathrm{~cm}$ wooden cage with a metal bottom, held $1.7 \mathrm{~m}$ from the ground by a metal post and located below the canopy of a walnut tree (bottom picture). We knew from previous observations that magpies foraged or perched regularly in both locations. The two feeders were placed $100 \mathrm{~m}$ from each other.

Figure S2. Details of radio-transmitter insertion into a walnut. The nut was split open with a knife, a portion of the kernel similar in weight to the transmitter was removed, the transmitter was inserted into the nut with the antenna rolled, and finally the two

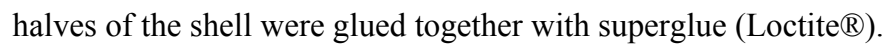

Supplementary Material 2. Video recording with a sensitive-movement camera in Feeder 1 on 27 October 2015, showing three magpies at once, and two of them retrieving a nut each (containing transmitters in this case). The time that appears in the video is local time, one hour ahead of solar time (thus, it was 8 am solar time). It can be observed that the second magpie that removed a nut flew westwards beyond a group of trees, being lost at a distance of ca. $130 \mathrm{~m}$ from the feeder. This transmitter was not found despite a thorough search at a distance up to $300 \mathrm{~m}$, and might represent an event of long-distance dispersal. 
Figure 1

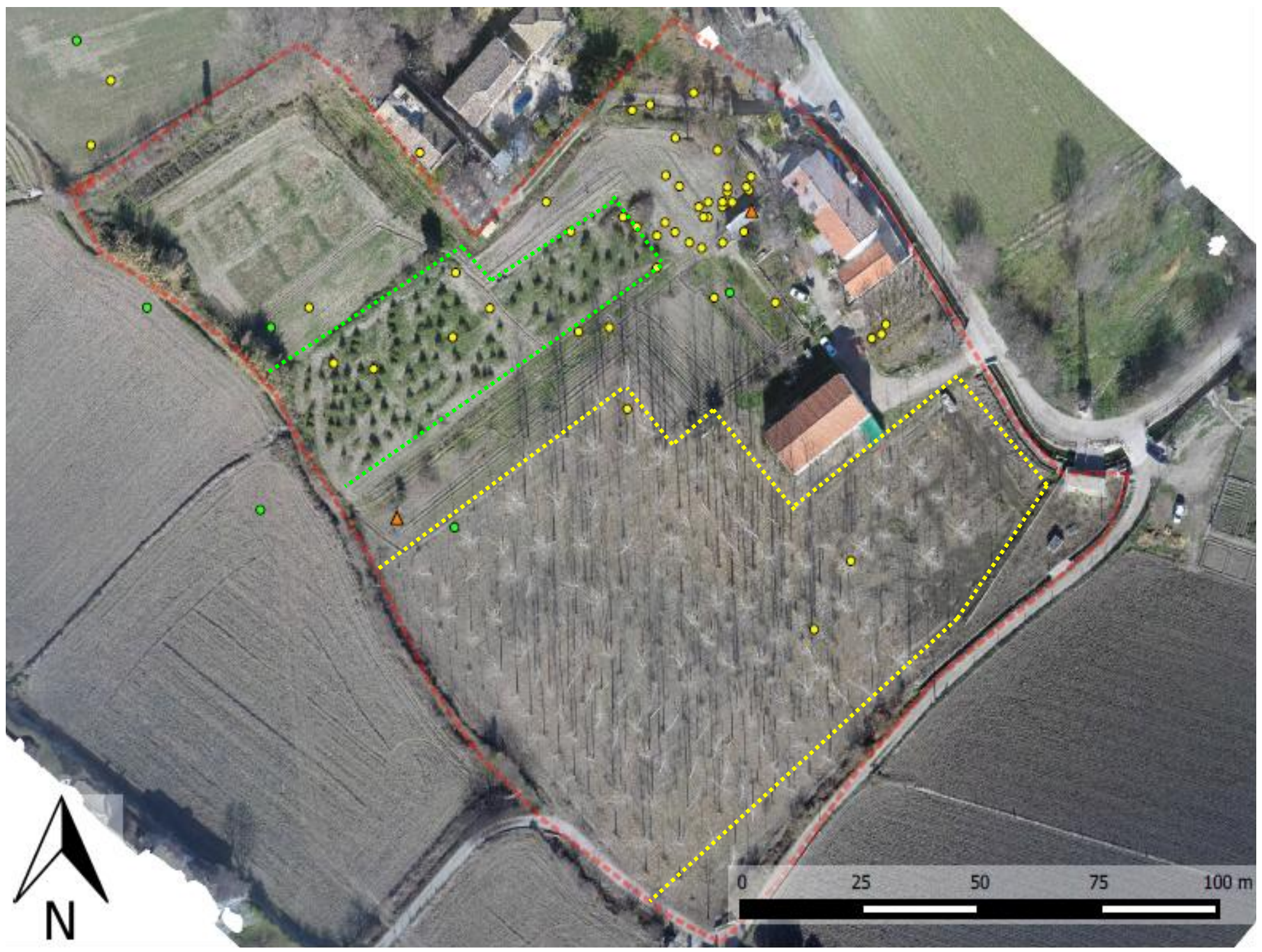


Figure 2
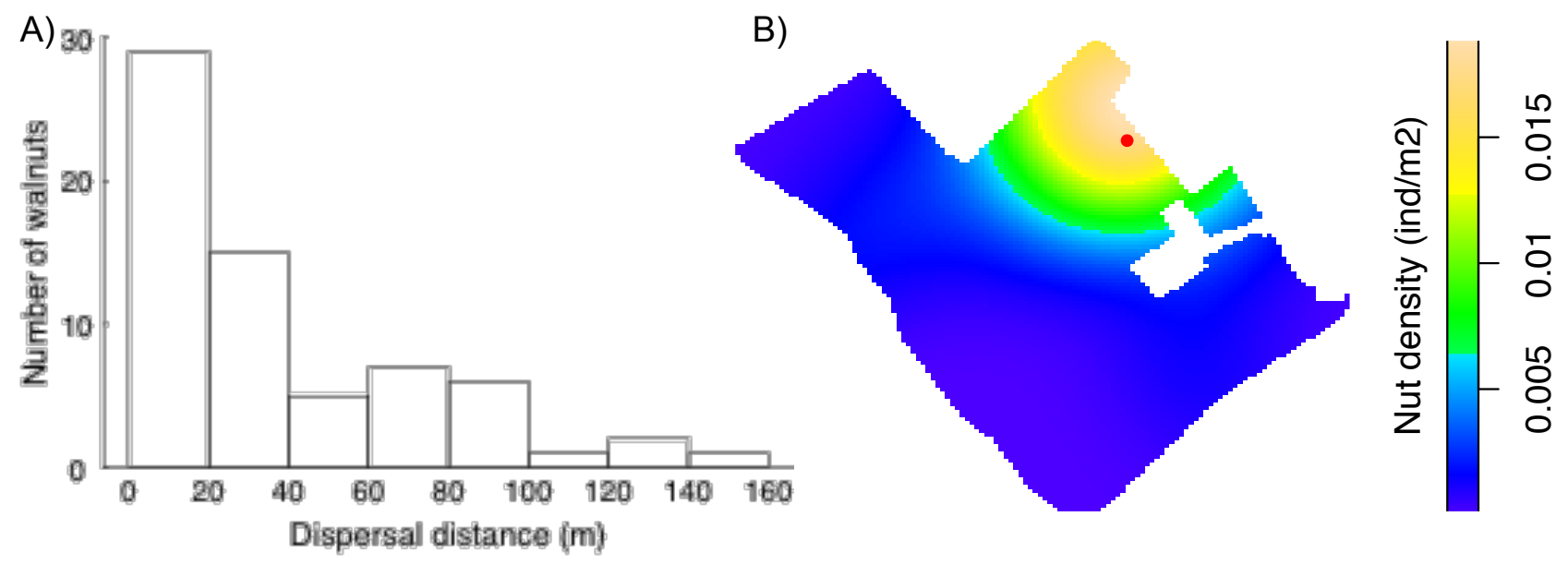
Figure 3

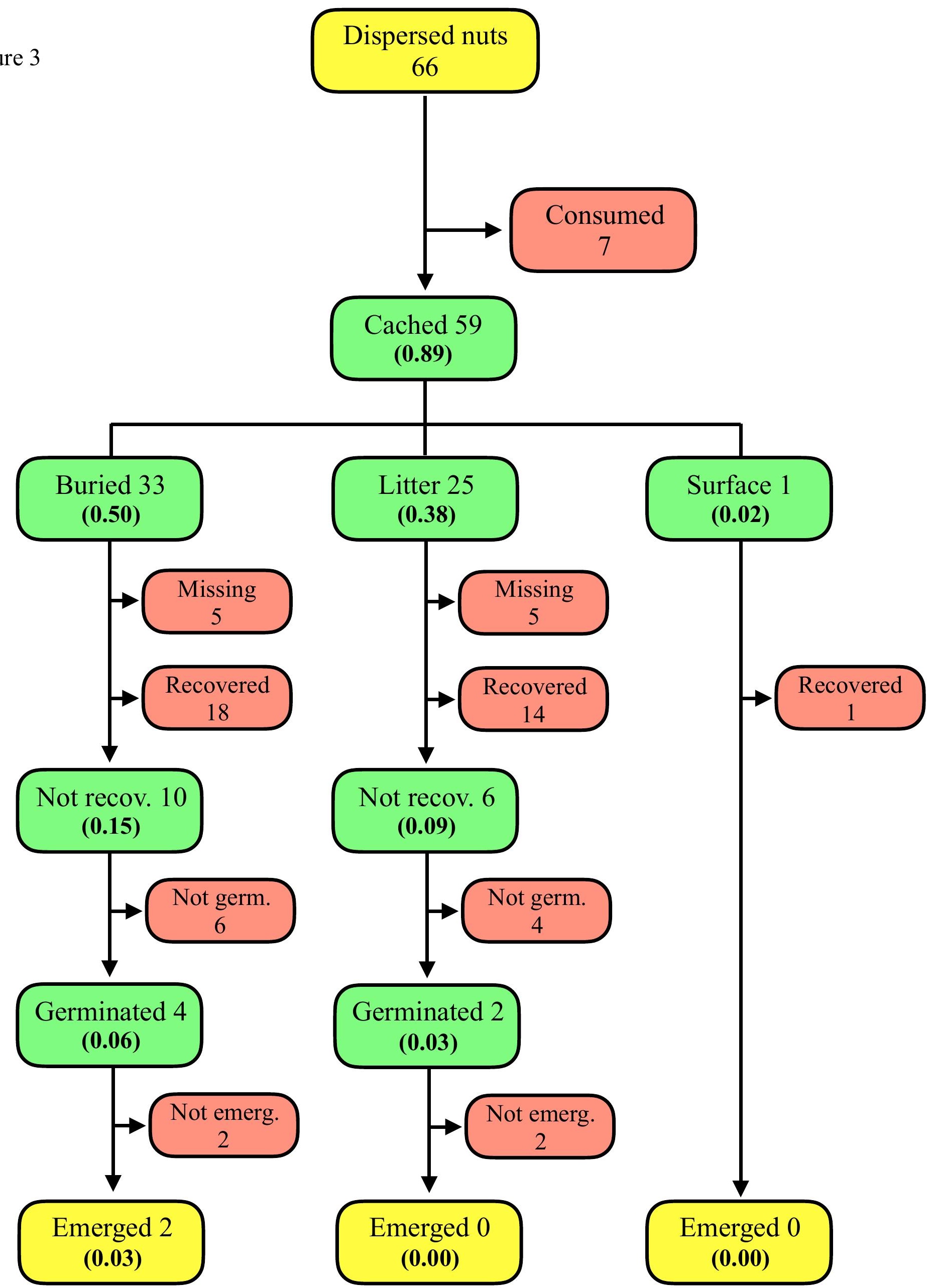


Supplementary Material 1, Figure S1
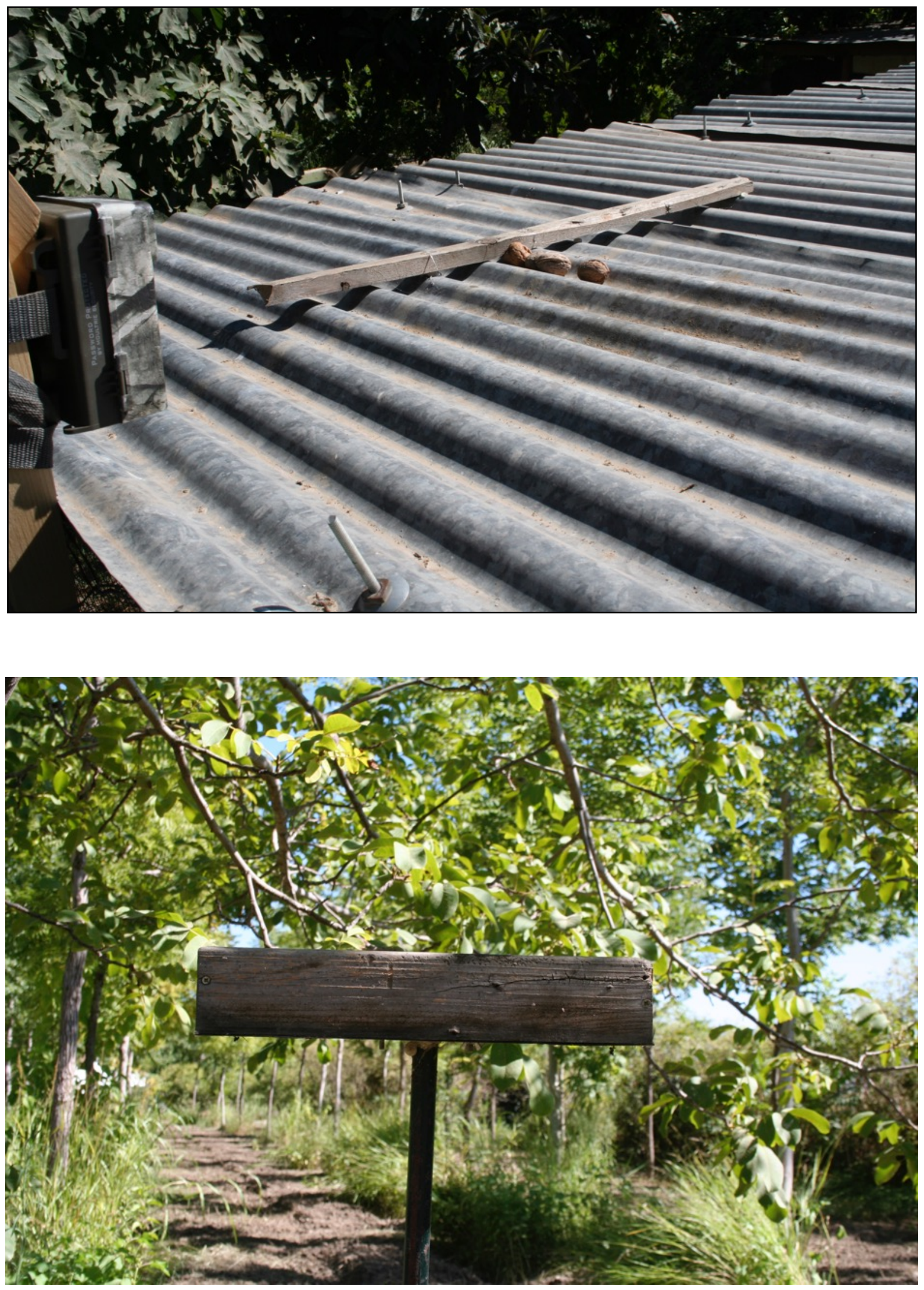
Supplementary Material 1, Figure S2

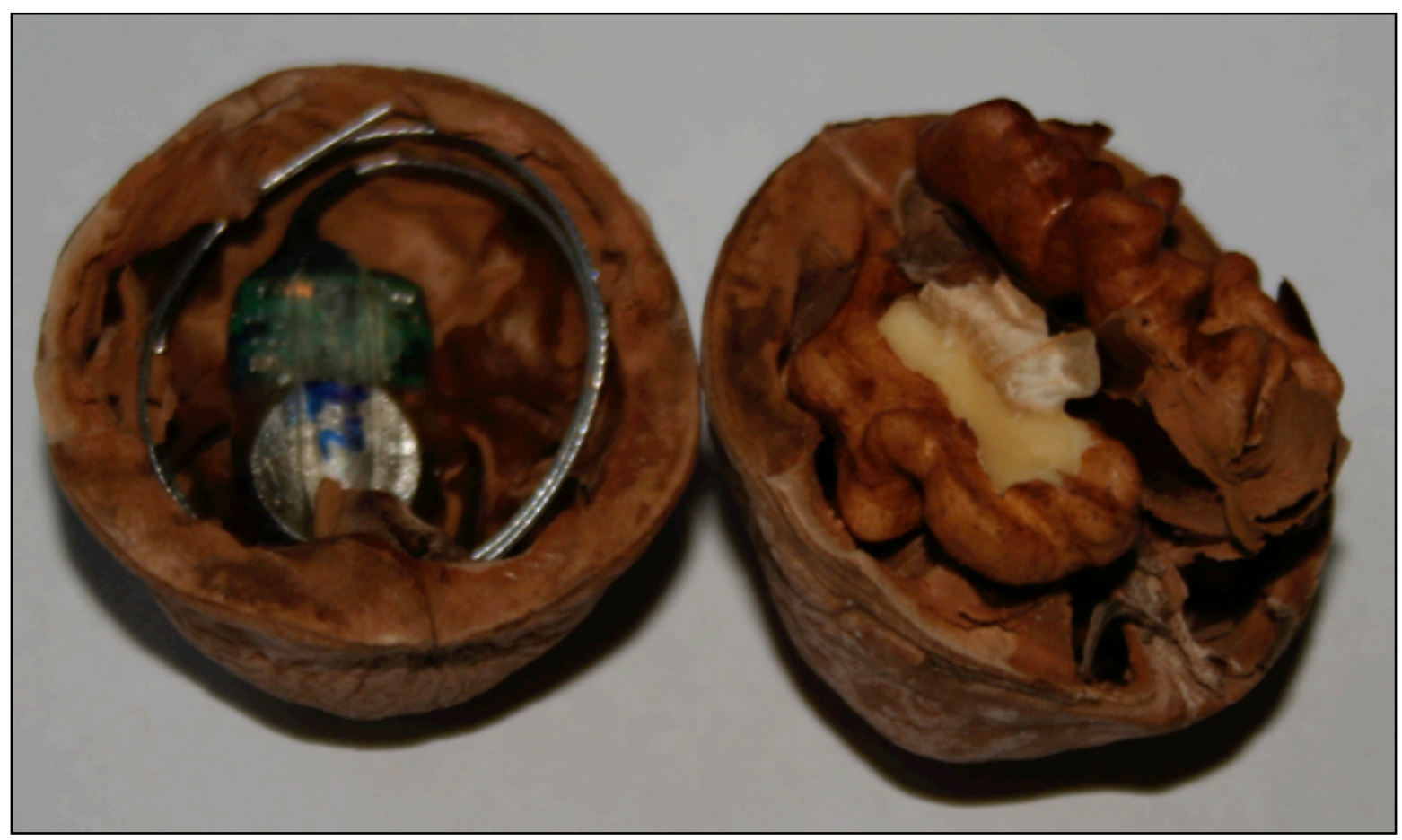


Click here to access/download Supplementary Material Castro et al Suppld Mat 2.AVI 